\title{
Protective effect of starch-stabilized selenium nanoparticles against the hepato-renal melamine-induced toxicity in male albino rats
}

Zainab Sabry Othman Ahmed ${ }^{1}$, Mona K. Galal ${ }^{2}$, Elsayed A. Drweesh ${ }^{3}$, Khaled S. Abou-ElSherbini $^{3}$, Eman A.M. Elzahany ${ }^{3}$, Mohamed M. Elnagar ${ }^{* 3,4}$, Noha A. E. Yasin ${ }^{* 1}$

${ }^{1}$ Cytology and Histology Department, Faculty of Veterinary Medicine, Cairo University, Giza 12211, Egypt.

${ }^{2}$ Biochemistry and Chemistry of Nutrition Department, Faculty of Veterinary Medicine, Cairo University, Giza 12211, Egypt.

${ }^{3}$ Inorganic Chemistry Department, National Research Centre, 33 El Bohouth St. (former Eltahrir St.), Dokki, Giza 12622, Egypt.

${ }^{4}$ Institute of Electrochemistry, Ulm University, Albert-Einstein-Allee 47, 89081 Ulm, Germany

\section{*Corresponding author:}

\section{Mohamed M. Elnagar}

Inorganic Chemistry Department, National Research Centre, 33 El Bohouth St. (former Eltahrir St.), Dokki, Giza 12622, Egypt.

Institute of Electrochemistry, Ulm University, Albert-Einstein-Allee 47, 89081 Ulm, Germany

E-mail address: mohamed.elnagar@uni-ulm.de

\section{Noha A. E. Yasin}

Cytology and Histology Department, Faculty of Veterinary Medicine, Cairo University, Giza 12211, Egypt.

E-mail address: nohayassin428@cu.edu.eg; nohayassin428@yahoo.com

Phone number: +201155833448 


\begin{abstract}
:
Melamine and its analogues are illegally added to falsify the content of protein in food products. The elevated concentrations of these compounds cause harmful effects in humans and animals. In this contribution, the potential ability of synthesized starch-stabilized selenium nanoparticles (SeNPs@starch) towards inhibiting the toxicity of melamine on the liver and kidneys has been systematically investigated. The Se-NPs@starch were characterized by XPS analysis, EDS mapping analysis, TEM, and FT-IR. Starch plays a crucial role in the stabilization and dispersion of Se NPs, as noticed from the TEM and EDS investigations. Furthermore, the atomic ratio of Se distribution over starch surface is approximately 1.67\%. To evaluate the activity of SeNPs@starch, this study was conducted on four groups of adult male rats. Group I (the control group), group II received Se-NPs@starch, group III received melamine, whereas group IV received melamine and Se-NPs@starch. The results reveal a significant alteration in the histoarchitecture of both hepatic and renal tissues induced by melamine. While melamine induces severe toxic effects on the hepatic and renal tissues, the administration of Se-NPs@starch results in remarkable protection of rats against melamine-induced toxicity. Collectively, the affordable starch-stabilized Se-NPs have a potent biological activity, making them auspicious candidates for biomedical applications.
\end{abstract}

\title{
Keywords:
}

Melamine-toxicity; Se-NPs@ starch; Immobilization. 


\section{Introduction}

Melamine is frequently used in different products as furniture, laminates, plastics, food utensils, coatings, glues, commercial filters, and dining ware [1]. Melamine intake at very low concentrations is harmless for animals because it is hardly metabolized by animals and rapidly eliminated via urine (more than 90\%) [2]. Furthermore, World Health Organization (WHO) and U.S. Food \& Drug Administration (USFDA) determined the safe level of melamine concentrations in human food materials to be $2.5 \mathrm{mg} / \mathrm{kg}$ [3]. However, melamine and its analogs including nitrogen-rich triazine compounds are illegally added to various foodstuffs to falsify the protein contents, resulting in fatal adverse effects in children and pets [4]. Recently, exposed dairy products containing melamine have raised concerns regarding its toxicity $[5,6]$. For example, nephrotoxicity was noticed among the children who ingested milk- infant formula contaminated with melamine [7]. Unfortunately, this outbreak was accompanied by urinary stones in both infants and children. As a consequence, 294,000 of them were influenced with more than 50,000 hospitalized and 6 died due to acute renal failure [8]. Besides, renal failure and death were reported in domesticated dogs and cats after exposure to pet food contaminated with melamine and its analogs [9-11].

Melamine can accumulate in the brain, liver, spleen, and bladder as an effect of oral administration over time [12]. The increase of melamine in these organs induces adverse effects on the growth of fetuses and neonates [13]. Likewise, ingestion of melamine leads to sperm abnormalities and DNA damage [14], in addition to detrimental impacts on the male reproductive system [15]. Testicular damage is observed to be associated with oxidative stress [16]. Oxidative stress is a pathophysiological phenomenon that emerges from the imbalance between the formation of reactive oxygen species (ROS) and the anti-oxidative efficiency of the enzymatic and nonenzymatic antioxidants [17]. Excessive ROS can cause alterations in the cellular macromolecules including lipids, proteins, and DNA, followed by a disruption of the cell wall, cellular enzymes inactivation, and eventually undergo cell death $[18,19]$. On that front, substantial efforts have been devoted to inhibiting melamine toxicity $[20,21]$.

Metal nanoparticles are of utmost importance in medicine and pharmacology due to their fascinating properties such as chemical stability, non-toxicity, and biocompatibility [22, 23]. 
Among them, selenium (Se) is a fundamental trace element required for the regular physiological function of growing animals [24], and is consumed from plants. Besides, Se is very important to human health because of its potent pro-oxidant, and antioxidant effects, anti-inflammatory and immunity-boosting capabilities [25, 26]. Remarkably, many Se compounds are reported to have significant anti-cancer activity and chemopreventive properties [27]. More outstandingly, Se NPs show an antiviral effect against the current pandemic of SARS-CoV-2 (coronavirus disease 2019) has been confirmed using Ebselen [26]. However, there is a very narrow boundary between the acceptable concentrations of Se intake and its toxicity [28]. Generally, the pro-oxidant and antioxidant effects, bioavailability, and toxicity of Se are strongly affected by its chemical form, particle size, and concentration. These properties are crucial to determine the interaction of Se with biological entities [29]. For example, the toxicity of Se is remarkably inhibited in the nano-size zerovalent form. Moreover, Se-NPs with particles size of 5-200 nm can efficiently scavenge free radicals such as superoxide anion and 1,1-diphenyl-2-picrylhydrazyl (DPPH) [30]. While selenomethionine is a very safe natural source of Se with high bioavailability, lower toxicity, and similar ability to increase selenoenzyme levels were detected for Se-NPs of average particle size of $36 \mathrm{~nm}$ [31]. Zhang et al. showed that Se-NPs in mice are seven times lower in toxicity than sodium selenite and three times lower than organic Se compounds [32]. Additionally, nanoparticle applications in the fisheries and livestock world revealed that Se-NPs enhance the efficacy of growth, digestion, immunomodulation, and reproduction [33] as well as increase the productivity of stress-ridden fish and livestock [34].

Despite the fascinating properties of NPs, they suffer from aggregation in suspensions due to their high surface energy, consequently, their activity sharply declines as a function of time [35]. Hence, to control the dispersion and size of Se-NPs, natural polysaccharides like chitosan [36], and cellulose [37] were used as natural stabilizers and size controlling agents. One should emphasize that the shelf-life storage of the stabilized NPs via the immobilization approach is extremely long and can exceed 5 years [35].

In this study, the starch-stabilized Se-NPs (Se-NPs@starch) were synthesized and characterized by XPS, FT-IR, and TEM. The potential activity of the synthesized starch-stabilized Se-NPs has 
been evaluated for the inhibition of the toxicity of hepatic and renal tissues induced by melamine ingestion. Experiments were conducted on four groups of male albino rats including group I (control), group II received starch-stabilized Se-NPs, group III received melamine, whereas group IV received both melamine and starch-stabilized Se-NPs. Statistical analysis of the results is also provided.

\section{Materials and methods}

\subsection{Chemicals and reagents}

Melamine $\left(\mathrm{C}_{3} \mathrm{H}_{6} \mathrm{~N}_{6}\right.$, LOBA Chemie, India) was obtained from El-Mekkawy Company, Cairo. Selenium (Sigma-Aldrich, CAS 7782-49-2 034-001-00-2), potato starch (CAS Number: 9005-258), ascorbic acid (CAS Number: 50-81-7), and nitric acid ( $\mathrm{HNO}_{3}, \mathrm{CAS}$ Number 7697-37-2) were of high-purity grade from Sigma-Aldrich.

\subsection{Methods}

\subsubsection{Selenous acid preparation}

$0.050 \mathrm{M}$ of selenous acid $\left(\mathrm{H}_{2} \mathrm{SnO}_{3}\right)$ was prepared by dissolving $0.987 \mathrm{~g}$ of Se metal in concentrated $\mathrm{HNO}_{3}$ before heating till dryness and dissolved in $250 \mathrm{~mL}$ distilled water [38].

\subsubsection{Preparation of selenium nanoparticles impregnated on starch (Se-NPs@starch)}

Se-NPs were synthesized in an eco-friendly and green synthesizing procedure through the application of starch as stabilizer and capping agent, and ascorbic acid functions as a reducing agent that reduces Se (IV) to Se. Se-NPs are stabilized in starch as mould plates according to the literature but with replacing cellulose by starch $[38,39]$. In details, the selenous acid / starch aqueous solution was prepared as follow: $50.0 \mathrm{~g}$ potato starch was boiled in 100 water and then mixed with $250 \mathrm{~mL}$ of $0.05 \mathrm{M}$ selenous acid before completing the total volume to $800 \mathrm{~mL}$. Afterward, $100 \mathrm{~mL}$ of $0.20 \mathrm{M}$ ascorbic acid solution was added dropwise into the selenous acid / starch solution to start the reduction reaction. After the addition of ascorbic acid, the solution changed from transparent to red, indicating the formation of Se-NPs. The obtained crimson red solution was concentrated to less than $100 \mathrm{~mL}$ using rotary evaporator at $80{ }^{\circ} \mathrm{C}$. A crimson red gel 
is formed, which is dried at $80{ }^{\circ} \mathrm{C}$ in an oven to produce shiny crimson red particles (SeNPs@starch).

The synthesized Se-NPs@ @starch was characterized by X-ray photoelectron spectroscopy (XPS), Fourier-transform infrared (FTIR), and Transmission Electron Microscope (TEM).

\subsection{Instrumentation}

To investigate the surface chemical composition and oxidation state of Se, X-ray photoelectron spectroscopy (XPS) analysis was conducted using a UHV Multiprobe system (Scienta Omicron, Germany) with a monochromatic X-ray source ( $\mathrm{Al} \mathrm{K \alpha}$ ) and an electron analyzer (Argus $\mathrm{CU}$ ) with $0.60 \mathrm{eV}$ energy resolution. Fourier-transform infrared (FTIR) spectra were recorded on a Nicolet iS10, Thermo-Fisher Scientific, USA, using a KBr pellet. The TEM images of Se-NPs@starch were obtained by a TEM of the Se-NPs@ @ starch using a JEOL model 1200EX electron microscope at an operating voltage of $120 \mathrm{kV}$.

\subsection{Experimental protocol and animal grouping}

\subsubsection{Experimental animals and ethical approval}

Adult male albino rats $(n=40$, average B.W $=200 \pm 20$ g) were kept in plastic cages under the standard hygienic conditions (60\% relative humidity, $24 \pm 3^{\circ} \mathrm{C}$ room temperature, and $12: 12-\mathrm{h}$ light: dark cycle with ad libitum access to food and drinking water). Rats were treated humanely according to NIH guidelines, and the experimental procedure was accepted by the Institutional Animal Care and Use Committee (IACUC) of the Faculty of Veterinary Medicine, Cairo University (Approval number Vet CU28042021291).

\subsubsection{Experimental design}


Rats were acclimated for one week, then they were assigned to 4 equal groups of ten each $(n=5$ rats/cage); the first group (untreated control group) only received distilled water, the second group: Se-NPs@starch treated group (2 mg Se-NPs/kg) as previously mentioned by Rashad et al. [37], the third group: melamine-treated group $(300 \mathrm{mg} / \mathrm{kg})$ as previously mentioned by An et al. [40], and the fourth group: Se-NPs@ @ starch co-treated group (received melamine (300 mg/kg) plus SeNPs $(2 \mathrm{mg} / \mathrm{kg}))$. All treatments were received daily by stomach tube for 4 successive weeks.

\subsection{Sample collection and preparation}

After 28 days of treatment, serum samples were obtained from rats for measuring the function of both liver and kidney. Then, rats were euthanized by cervical dislocation for collection of the liver and kidney samples. Some specimens of these organs were stored at $-80{ }^{\circ} \mathrm{C}$ for estimation of oxidative stress biomarkers in their tissue homogenates and quantitative real-time PCR (Rt-PCR) analysis for some antioxidant- and some apoptotic- related genes, while other specimens were histopathologically and immunohistochemically investigated after fixation in 10\% neutralbuffered formalin (NBF) solution.

\subsection{Biochemical analysis}

\subsubsection{Determination of Liver Function Markers}

The activities of both serum aspartate- and alanine- aminotransferase (AST \& ALT) were assayed using reagent kits (Spectrum Diagnostics Co., Egypt) following the provided instructions.

\subsubsection{Determination of kidney Function Markers}

The levels of serum creatinine and urea were assayed using reagent kits (Spectrum Diagnostics Co.) following the provided instructions.

\subsubsection{Hepatic and renal oxidative stress biomarkers}


A Teflon tissue homogenizer was used to homogenize both liver and kidney samples in 10\% (W/V) ice-cold 0.1 M phosphate buffer saline (PBS) (pH 7.4). Crude tissue homogenate was centrifuged at $15,000 \mathrm{rpm}$ for $15 \mathrm{~min}$ at $4{ }^{\circ} \mathrm{C}$ and subsequently used for determination of reduced glutathione (GSH) content as previously mentioned by Ellman [41], malondialdehyde (MDA) content according to Ohkawa et al. [42], in addition to total protein concentration as previously reported by Bradford [43].

\subsection{4. qRT-PCR analysis for Nrf-2, GPx, c-Myc, and CASP 3 genes}

The relative hepatic and renal Nrf-2, GPx, c-Myc, and CASP 3 mRNA abundance was determined by qRT-PCR analysis using GAPDH as a housekeeping gene. Total RNA was extracted from approximately $100 \mathrm{mg}$ liver and kidney tissues using the total RNA Extraction Kit (Vivantis, Malaysia). By using M-MuLV Reverse Transcriptase (NEB\#M0253). RT-PCR was carried out after confirming the concentration and purity of RNA. By fluorescence-based real-time detection method with a fluorescent SYBR Green dye (Thermo Scientific, Cat. No. K0221), a quantitative assessment of cDNA amplification for each gene was performed. The primer sequence used for RT-PCR analysis was shown in Table (1). The real-time PCR conditions were carried out as follow: $95{ }^{\circ} \mathrm{C}$ for $5 \mathrm{~min}$ (initial denaturation) and then 40 cycles at $95{ }^{\circ} \mathrm{C}$ for $15 \mathrm{~s}, 60^{\circ} \mathrm{C}$ for $30 \mathrm{~s}$, and $72{ }^{\circ} \mathrm{C}$ for $30 \mathrm{~s}$ in each experiment. Negative controls that were free of the template were included. Each qRT-PCR was performed with three biological replicates, and each biological replicate was assessed three times. Using the comparative $2^{-\Delta \Delta C T}$ method, the relative transcription levels were calculated [44].

\subsection{Histopathology}




\subsubsection{Light microscopy (L.M.)}

Both liver and kidney specimens from all groups were immediately fixed for $48-72 \mathrm{~h}$ in $10 \% \mathrm{NBF}$, embedded in increasing grades of alcohol. Then, tissue specimens were cleared with xylene and fixed in paraffin. 3-4 $\mu \mathrm{m}$ paraffin sections were processed for staining with hematoxylin and eosin (H\&E) for histopathological investigation as described by Bancroft and Gamble [45].

\subsubsection{Immunohistochemical analysis}

Immunohistochemistry was carried out on deparaffinized hepatic and renal sections (4- $\mu \mathrm{m}$ thick) for detection of apoptosis according to the manufacturer's protocol. Sections were immersed in $0.3 \%$ hydrogen peroxide $\left(\mathrm{H}_{2} \mathrm{O}_{2}\right)$ in PBS for 20 min for deactivation of endogenous peroxidase, incubated with rabbit polyclonal anti-caspase-3 antibodies (active/cleaved) (100-56113, Novus biologicals) 1:100 for $1 \mathrm{hr}$ then washed out. After that, tissue sections were incubated for $20 \mathrm{~min}$ with secondary antibody Horse Radish peroxidase (HRP) Envision Kit (DAKO), washed out, and incubated for 10-15 min with diaminobenzidine (DAB). Sections were washed, counterstained in hematoxylin, dehydrated in alcohol, cleared with xylene, and covered with a coverslip for microscopic examination.

Caspase 3 -stained liver and kidney sections were assessed using Leica Quin 500 software (Leica Microsystems, Switzerland) for morphological analysis. Caspase 3 immunostaining was quantified as area percentage in different slides ( $\mathrm{n}=5$ fields/group) at magnification power $\mathrm{x} 400$. The areas displaying brown color immunoreaction (positive) were selected for estimation. Mean values and standard error mean (SEM) of each specimen were obtained and statistically analyzed.

\subsection{Statistical analysis}


Descriptive statistics were presented as mean \pm SEM. The obtained results were subjected to oneway analysis of variance (ANOVA) using SPSS version 25.0 software (IBM, USA) followed by Tukey post hoc test. Data were considered significantly different at $P$-value less than 0.05 .

\section{Results}

\subsection{Characterization}

XPS investigations were carried out to identify the surface chemical composition of SeNPs@starch and the valence state of Se. Fig. 1a shows the XPS spectra (survey) of the SeNPs@starch sample. From the survey spectra, the peaks corresponding to Se, O, and C are observed. The high-resolution spectrum of Se implies the peaks of Se $3 d_{5 / 2}$ and $\operatorname{Se} 3 d_{2 / 3}$ at approximately 55.6 and $56.6 \mathrm{eV}$, respectively confirming the presence of elemental selenium $\left(\mathrm{Se}^{0}\right)$, as shown in Fig. 1b. Furthermore, the absence of Se 2p, 2s, and 1s peaks indicates that Se (IV) was entirely reduced during the synthesis of the Se-NPs@starch [46]. Besides $\mathrm{Se}^{0}$, the sample contained organic material on the surface as revealed by the presence of $\mathrm{C}$, and $\mathrm{O}$ (Fig. 1c). The C 1s peak in the XPS spectrum of starch has been deconvoluted into three peaks at 284.80, 286.4, and $288.7 \mathrm{eV}$, as presented in Fig. 1c [47].

The FTIR spectra of the Se-NPs@ $@$ starch and starch were measured in the range of $400-4000 \mathrm{~cm}^{-1}$, as shown in Fig. 2. The bands observed in both spectra at around $3260 \mathrm{~cm}^{-1}, 2931 \mathrm{~cm}^{-1}$, and 1635 $\mathrm{cm}^{-1}$, are correlated to $\mathrm{O}-\mathrm{H}$ stretching vibration, $\mathrm{C}-\mathrm{H}$ stretching, and $\mathrm{C}-\mathrm{O}$ bending vibration associated with the $\mathrm{OH}$ group, respectively [48]. The presence of Se-NPs connected to starch is confirmed by a red-shift of about $5 \mathrm{~cm}^{-1}$ for $\mathrm{OH}$ stretching vibration as well as the band at 763 $\mathrm{cm}^{-1}$ [49]. Additionally, a very clear band of Se-NPs at $643 \mathrm{~cm}^{-1}$ is noticed in the spectrum which is characterized for the spherical shape of Se-NP [50-52].

TEM micrographs of Se-NPs@starch (Fig. 3a and 3b) show Se-NPs in a dark spherical shape characterized by particle size ranging from 20 to $140 \mathrm{~nm}$ impregnated on starch.

The energy dispersive spectroscopy (EDS) mapping analysis reveals the peaks corresponding to C, O, and Se confirming the successful synthesis of Se-NPs@starch, as shown in Figure 3c. Notably, Fig. 3c demonstrates that Se with an atomic mass of $1.67 \%$ is distributed homogeneously over the starch surface. This low concentration of Se immobilized on starch is beneficial for 
biological applications since there is a very narrow boundary between the acceptable concentrations of Se intake and its toxicity. Furthermore, the homogenous distribution of Se-NPs over the starch surface indicates the potential ability of starch to stabilize Se-NPs against agglomeration.

\subsection{Liver and kidney functions}

Hepatic damage was estimated by the determination of ALT and AST activities. Fig. 4A revealed that melamine significantly elevated ALT activity from 41.81 U/L to 92.14 U/L and AST activity from 93.42 U/L to 105.22 U/L compared to the control.Co-treatment with Se-NPs@ starch showed a marked reduction in ALT activity to 47.33 and a non-significant decrease in AST activity to 96.46 when compared with the melamine-intoxicated group.

Renal damage was estimated by the determination of serum urea and creatinine levels. Fig. 4B revealed that melamine significantly increased serum urea level from 14.84 to $22.48 \mathrm{mg} / \mathrm{dL}$ and creatinine level from 0.75 to $1.50 \mathrm{mg} / \mathrm{dL}$ compared to the control group. Co-administration of SeNPs@starch non significantly decreased serum urea level to $18.96 \mathrm{mg} / \mathrm{dL}$ and significantly decreased creatinine level to $0.84 \mathrm{mg} / \mathrm{dL}$ when compared with the melamine-intoxicated group.

\subsection{Hepatic and renal oxidative stress biomarkers}

For studying the redox state of the cell, MDA (LPO biomarker) and some antioxidant machineries were estimated.

\subsubsection{Hepatic and renal MDA Content}

Based on our obtained results in Fig. 5, melamine markedly $(p<0.05)$ increased hepatic and renal MDA level from 1.53 to $5.22 \mu \mathrm{M} / \mathrm{mg}$ and from 1.08 to $3.50 \mu \mathrm{M} / \mathrm{mg}$ protein, respectively, compared to the control group. Co-administration with Se-NPs@starch significantly declined both liver and kidney MDA contents to $2.30 \mu \mathrm{M} / \mathrm{mg}$ protein and $2.10 \mu \mathrm{M} / \mathrm{mg}$ protein, respectively, compared to the melamine-intoxicated group.

\subsubsection{Antioxidant Machinery}


Antioxidant Machinery was estimated by the determination of GSH content and mRNA relative expression for $N r f-2$ and $G P x$ genes.

\subsubsection{Hepatic and renal GSH content}

Our current results in Fig. 6 indicated that melamine significantly depressed hepatic and renal GSH content from 3.83 to $2.47 \mu \mathrm{M} \mathrm{mg}^{-1}$ and from 3.62 to $2.31 \mu \mathrm{M} \mathrm{mg}^{-1}$ protein, respectively, compared to the control group. Co-administration with Se-NPs@starch significantly increased both liver and kidney GSH contents to $3.01 \mu \mathrm{M} / \mathrm{mg}$ protein and $3.03 \mu \mathrm{M} / \mathrm{mg}$ protein, respectively, compared to the melamine-intoxicated group.

\subsubsection{Hepatic and Renal mRNA relative expression for some antioxidant related genes (Nrf -2 and GPx)}

In the melamine-intoxicated group, the $N r f-2$ gene was significantly downregulated to 0.28 -fold and 0.16-fold compared with the control one in both liver and kidney tissues, respectively. While co-administration with Se-NPs@starch modulated the gene expression level to 0.71-fold in the liver and 0.40 -fold in the kidney. Such change in the gene expression was a significant increase when compared with the melamine-intoxicated group (Fig. 7).

Furthermore, in the melamine-intoxicated group, the GPX gene showed significant downregulation in both hepatic and renal tissues compared to the control one. Se-NPs@starch co-administration significantly elevated the expression level of the GPx gene from 0.2 to 0.7 -fold and from 0.2 to 0.82-fold compared with the melamine-intoxicated group in liver and kidney tissues, respectively (Fig. 7).

\section{Hepatic and Renal mRNA relative expression for some apoptotic-related genes (c-Myc and CASP 3)}

Melamine significantly upregulated c-Myc gene expression in both hepatic and renal tissues compared to the control group. While Se-NPs@starch co-administration significantly decreased the expression level of the c-Myc gene from 4 to 1.62-fold and from 6.20 to 1.8-fold in both liver and kidney, respectively (Fig. 8). 
Compared to the negative control group, the expression level of the CASP 3 gene was significantly upregulated in the melamine-intoxicated group, particularly in the kidney tissues. Se-NPs@starch co-treatment significantly modulated the expression level of CASP 3 gene from 6.51 to 3.73 -fold and from 8.3 to 2 - fold in both hepatic and renal tissues, respectively, compared to the melamineintoxicated group (Fig. 8).

\section{Histopathological investigations}

The microscopical examination of the hepatic sections from the control group revealed a normal histological architecture of the liver that appeared with normal radiating cords of hepatocytes, normal central vein, and blood sinusoids (Fig. 9a). The Se-NPs@starch exposed group exhibited nearly normal hepatocytes that appeared polyhedral with normal vesicular and central nuclei and arranged in hepatic cords that were radiating from the central vein. The hepatic cords were separated by normal blood sinusoids. In addition, the portal triad showed the normal histological structure of the bile duct and branches of the portal vein and hepatic artery (Fig. 9b, c). The melamine-exposed rats revealed hepatic tissues with severe damage that was observed in the form of distortion of the hepatic cord's arrangement, edema, severe congestion, and dilatation of the central vein. Blood sinusoids appeared severely dilated with clearly observed activated Von Kupffer cells. Furthermore, hepatocytes displayed severe ballooning and remarkable cytoplasmic vacuolization and showed different stages of degeneration and apoptosis. The dark brown deposition was also noticed inside the cytoplasm of hepatocytes. The portal area was disrupted, and the lining epithelium of the bile duct revealed distortion, in addition to inflammatory cells infiltration and severe congestion of the portal vein (Fig. 9d-j). On the other hand, the melamineexposed group co-treated with Se-NPs@starch exhibited partial recovery of the hepatic damage. The central vein appeared less congested with normal dilatation, while the blood sinusoids appeared with normal architecture. Some hepatocytes showed degeneration and ballooning with cytoplasmic vacuolization, but these alterations in the hepatic architecture were less in severity (Fig. 9k, l) when compared to the melamine exposed group without Se-NPs@ starch treatment.

Additionally, microscopical examination of the renal tissues from the control group revealed a normal histological structure of the renal cortex [renal corpuscle, proximal and distal convoluted tubules (PCT \& DCT)] (Fig. 10a), and the renal medulla (Fig. 10i). The Se-NPs@ starch exposed 
group revealed nearly normal glomerular tuft with plentiful capsular space enveloped by intact Bowman's capsule, intact tubular epithelial cells of PCT, DCT (Fig. 10b), and the renal medulla containing collecting tubules (Fig. 10j).

Conversely, renal tissue sections from the melamine-exposed group exhibited various histopathological alterations in the renal corpuscles, glomeruli, PCT, DCT, renal vasculature (Fig. 10c-g), and the collecting tubules (Fig. 10k). Some renal corpuscles revealed widening of Bowman's capsule (Fig. 10c-e) and widening of capsular space (Fig. 10c, d), while others showed distortion and shrinkage of Bowman's capsule (Fig. 10f, g) with narrowed capsular space (Fig. 10e). Congestion of glomerular capillary tuft (Fig. 10c-g) and diminished glomeruli with a prominent nuclear condensation were also observed (Fig. 10f, g). Moreover, some renal corpuscles revealed loss of glomeruli with a decreased number (hypocellularity) of mesangial cells (Fig. 10c), while others showed complete loss of cells (Fig. 10d). Peri-glomerular edema was also plentiful (Fig. 10d). In addition, degeneration, and necrosis of PCT and DCT with desquamated epithelial cells were detected (Fig. 10d-g). Also, some DCT was lined by squamous cells and possessed vacuolization and desquamation of other lining cells with pyknosis (Fig. 10d). Severe interstitial (Fig. 10c) and vascular (Fig. 10g) congestion in addition to hyalinization (Fig. 10f,g) were noticed. Furthermore, vacuolar degeneration of collecting tubules, hyalinization, and congestion of interstitial blood capillaries were prominent (Fig. 10k). On the other hand, the melamine-exposed group co-treated with Se-NPs@starch demonstrated partial recovery of the renal damage. The renal cortex and medulla appeared nearly normal with less degeneration, congestion, and hyalinization (Fig. 10h, l).

\section{Immunohistochemical finding}

According to our immunohistochemical findings in Fig. 11, liver sections obtained from both control and Se-NPs@ starch exposed rats exhibited a negative reaction to caspase 3, while a strong immuno-expression was noticed in the melamine-exposed one. However, the liver sections obtained from the group exposed to melamine and co-treated with Se-NPs@starch revealed a mild expression of caspase 3 (Fig. 11). 
On the other hand, renal tissues of both control and Se-NPs@ starch exposed group displayed mild positive immunoreactivity to caspase 3 . In contrast, the melamine-exposed group revealed a strong positive immune reaction. However, a moderate immunoreactivity was noticed in the melamineintoxicated group co-treated with Se-NPs@starch (Fig. 12).

Additionally, according to the data analysis, the melamine-intoxicated group demonstrated a remarkable elevation $(p<0.05)$ in the area\% covered by caspase 3 in both hepatic and renal tissues when compared to the control and Se-NPs@starch exposed group. On the other hand, the concurrent administration of Se-NPs@ @starch significantly $(p<0.05)$ reduced the caspase 3 area\% induced by melamine in both hepatic and renal tissues by $87.92 \%$ and $65.9 \%$, respectively, compared with the melamine-intoxicated group (Fig.13).

\section{Discussion}

The kidney is the major target organ in melamine toxicity, but there are some other tissues like the liver, muscles, colon, and spleen that were investigated for melamine toxicity [53]. This study has been focused on testing the ability of oral administration of Se-NPs@ starch to attenuate melamineinduced liver and kidney dysfunction. Therefore, the serum AST and ALT activities were assessed as the principal hallmarks of liver toxicity [54]. According to the present investigation, melamine induces severe hepatic damage as represented by markedly elevated serum functions of AST and ALT which further evidenced by severe histopathological alternations in the normal structure of hepatic tissues as shown in Fig. 9 (d-j) that indicated severe damage of the cellular membrane followed by leakage of hepatic enzymes into the bloodstream [55]. These results are in good agreement with those reported recently by Abd-Elhakim et al. [21]. However, treatment with SeNPs@starch in group IV markedly decreased the serum activities of both ALT and AST, in addition to improvement in liver functions, which are highly indicative of the hepatoprotective effect of Se-NPs@starch on melamine-induced hepatic impairment. These findings are consistent with Bai et al. and Sohrabi et al. [56, 57]. Additionally, the ameliorative effects of Se-NPs@ starch were also evidenced by the less hepatocellular damage observed in the histopathological examination of liver tissues as shown in Fig. $9(\mathbf{k} \& \mathbf{l})$. These results are in harmony with that documented by Amin et al., Bai et al. and Hamza et al. [56, 58, 59]. These outcomes may be attributed to maintaining the hepatocyte's integrity or regeneration of damaged hepatocytes [60]. 
Furthermore, urea is considered the initial acute renal biomarker that elevates by any type of renal injury. While creatinine only elevates when most of the kidney function is lost, therefore, it is considered the most reliable renal indicator [61]. Consequently, any significant elevation in the serum urea and creatinine levels can indicate kidney damage. Our obtained results revealed that melamine-intoxicated rats exhibited a significant elevation in the serum creatinine and urea levels, indicating melamine-induced renal glomerular impairment. These outcomes are consistent with those of Al-Seeni et al. and Abd-Elhakim et al. [21, 62]. Moreover, the renal damage induced by melamine was evidenced histopathologically by severe deterioration of renal architecture as in Fig. 10 (c-g \& k) which was also observed by Lee et al. [63] and Abd-Elhakim et al. [21] after exposure to melamine and the findings of Lee et al. [63], Yasui et al. [64] and Peerakietkhajorn et al. [65] after exposure to melamine plus cyanuric acid. Conversely, concomitant administration of Se-NPs@starch with melamine significantly decreased the serum urea and creatinine levels. Moreover, administration of Se-NPs@starch substantially restores the melamine-induced histological alterations to the kidney tissues as in Fig. 10 (h \& l) supporting the nephroprotective property of Se-NPs@starch against melamine toxicity. These results agree with the results obtained by others $[66,67]$. The nephroprotective efficiency role of the Se-NPs@ starch could be due to its potent action in scavenging free radicals [68], thus protect the cellular structure from oxidative damage [69].

Based on the obtained findings, oxidative stress and apoptosis are involved in the pathophysiology of the hepato-renal toxicity induced by melamine. Here, the levels of lipid peroxidation marker and GSH, in addition to mRNA expression level for GPx and Nrf2 were assessed to evaluate the level of oxidative stress. Compared to the control, the MDA level in both tissue homogenates was strongly elevated, while the content of GSH and the mRNA expression level for GPx were significantly reduced in the melamine-intoxicated rats. Therefore, our results suggest that melamine elevated the susceptibility of tissue to oxidative damage via increasing oxidative stress and reduction of endogenous antioxidant capacity in both tissues. Our findings coincide with previous results stated by Al-Seeni et al. and Abd-Elhakim et al. [21, 62].

A marked elevation of MDA concentration reflected the severity of cell damage resulted from the oxidation of unsaturated fatty acids. While a significant depletion in antioxidant enzymes (GPx and GSH) reflected the impaired antioxidant defense mechanism to counteract the elevated levels 
of free radicals [70]. The molecular mechanism underlying the hepato-renal damage induced by melamine is not entirely clear. According to our obtained results, melamine administration induced hepato-renal oxidative damage as substantiated by marked downregulation for Nrf2 mRNA gene expression. As reported, Nrf2 is a key transcription factor that has a critical contributor role to protect cells from damage induced by inflammation and oxidative stress. Translocation of Nrf2, from the cytoplasm to the nucleus, was necessary for its regulation of antioxidant/detoxification enzyme expression [71]. As observed in our study, melamine downregulates the Nrf2 mRNA level. This is an actual indicator of an oxidative stress response. On the other hand, Se-NPs@starch coadministered group (group IV) significantly reduced the level of MDA, stabilized nonenzymatic antioxidant GSH level, and up-regulated antioxidant enzyme (GPx) mRNA expression level in the liver and kidneys. Thus, these findings suggest an ameliorating effect of Se-NPs@starch against melamine-induced excessive production of ROS. Se-NPs@starch administration led to antioxidative and nephron-protective effects as was reported by Khater et al. [67]. Also, the antioxidant activity of Se-NPs@ starch was reported by Bai et al. and Sheiha et al. [56, 72] for liver tissue and this finding comes beside our results. Moreover, selenium can combat oxidative stress, consequently leading to the cellular redox balance, due to its incorporation as selenocysteine into GPx and thioredoxin reductase [72]. Se-NPs@starch lead to increase activities of both GPx and glutathione S-transferase, resulting in less oxidative stress [30, 67]. In addition, Se-NPs@starch detoxify hydroperoxidase and lipid peroxides that accumulate in the cytoplasm and mitochondria. Also, Se improves the antioxidant enzyme capacity, thereby leading to cellular protection from oxidative damage [73]. Our results confirm the curative effect of Se-NPs@starch on both hepatic and renal tissues that may be due to the ability of Se-NPs@starch to mitigate the oxidative stress induced by melamine through decline the production of ROS and thus inhibiting the free radical chain reactions. Khalaf et al. and Rashad et al. [37, 74] verified the antioxidant effect of SeNPs@starch. Furthermore, most recent studies link the potent antioxidant effects of Se with the activation of the Nrf2 factor. Se was reported to upregulate the transcription of Nrf2 against metal intoxication [75], as observed in our result. The elevated levels of oxidative stress may hinder the pathway of Nrf2 and thereby enhancing the deleterious effects induced by toxic agents [76]. Zhang et al. reported that selenium triggered the Nrf2 activation and thereby upregulating the transcription of many genes like glutathione S-transferase [77]. Concerning cell death, a series of physiological symptoms is initiated as a result of several biochemical lesions induced by the rapid 
reaction of free radicals with cellular elements that eventually lead to apoptosis. Therefore, our study strongly recommends using of Se-NPs@starch as a potent antioxidant to diminish the apoptosis induced by melamine intoxication in both hepatic and renal tissues. In the current study, intoxication with melamine significantly induced overexpression of the mRNA expression level of both apoptotic genes; caspase-3 and c-Myc. This result is in harmony with that of Hsieh et al. [78]. This was confirmed by a significant strong positive caspase 3 immunoreactivities of hepatorenal tissues in melamine-intoxicated rats as presented in Fig. 11, 12 \&13. Activation of caspase 3 can be triggered either by extrinsic or intrinsic factors inducing mitochondrial stress, and it plays important role in cell apoptosis [79]. Activation of caspase 3 is an important hallmark of DNA fragmentation and nuclear condensation in apoptotic cells $[66,80]$. c-Myc is a potent transcription factor that regulates the proliferation, growth, and differentiation of cells, whereas deregulation of c-Myc as in the situation of cellular stress induces apoptosis [81] and suggested that Bax and caspase activation are involved in c-Myc induced apoptosis. The hepato-renal cell death induced by melamine may be attributed to the excessive release of ROS after mitochondrial dysfunction. Yiu et al. reported that melamine activates $\mathrm{Ca} 2$-sensing receptors which in turn causes a sustained $\mathrm{Ca} 2$ entry in the cell [82]. Cell death may be mediated either by ROS generation together with elevation of $\mathrm{Ca}$ ions inducing a caspase-mediated apoptotic pathway or through activation of the mitochondrial proapoptotic (Bax-1/ Bcl-2) pathway and ROS-mediated cytotoxicity [53]. Therefore, the potent anti-apoptotic activity of affordable Se-NPs@starch has been commonly postulated as one of the vital mechanisms underlying its beneficial bioactive properties. This activity was previously reported [83]. Many studies have shown the potential ameliorative effect of Se-NPs@starch against oxidative stress, nuclear damage, and cell death [74, 83] that may be due to the ability of Se-NPs@starch to enhance the antioxidant defense mechanism, scavenge free radicals efficiently [84], upregulate $\mathrm{Nrf} 2$ and heme oxygenase-1, as well as impede the inflammatory response and apoptotic cascade [83].

\section{Conclusion}

Starch can stabilize Se-NPs effectively as confirmed by XPS, EDS elemental mapping, and TEM investigations. The synthesized Se-NPs via the proposed approach are well-dispersed and biocompatible, in which both features are of major importance for the potential application of metal nanoparticles in medicine. Melamine ingestion can induce a severe toxic effect on the liver 
and kidneys. The intoxication with melamine resulted in an elevation of ALT, AST, serum urea, and creatinine, in addition to increased MDA, the high expression level of the apoptosis-related gene, reduced GSH and decreased expression level of antioxidant genes. These findings were associated with a strong positive immune expression of caspase-3 and severe distortion and alteration in the hepatorenal tissues. Fascinatingly, the daily oral administration of starch-stabilized Se-NPs ( $2 \mathrm{mg}$ Se-NPs/kg/day) for 4 successive weeks can significantly reduce the apoptotic effect generated by melamine intoxication (300 mg melamine/kg/day) in the liver and kidney tissues of adult rats. Moreover, concomitant administration of starch-stabilized Se-NPs with melamine can substantially improve the liver and kidney function parameters, alleviate the oxidative stress, apoptosis, and histopathological injuries exerted by melamine.

\section{Funding}

This study received no support from public, private, or non-profit funding agencies.

\section{Data Availability}

Not applicable

\section{Conflict of interest}

The authors declare no known competing interests.

\section{Authors' contributions}

All authors conceived the study and designed the experimental protocol. Drweesh E.A., Abou-ElSherbini K.S., Elzahany E.A.M., and Elnagar M.M. prepared and described the X-ray photoelectron spectroscopy (XPS), Fourier-transform infrared (FTIR), and transmission electron microscope (TEM) observations for the produced Se-NPs in comparison with the stabilizing agent and embedding host (starch). Ahmed Z.S.O. and Yasin N.A.E. performed the histopathological and immunohistochemical investigations and drafted the manuscript. Galal M.K. performed the biochemical and molecular assays. All authors read, revised, and approved the final manuscript. 


\section{Ethical Approval}

Rats were treated humanely according to NIH guidelines, and the experimental procedure was accepted by the Institutional Animal Care and Use Committee (IACUC) of the Faculty of Veterinary Medicine, Cairo University (Approval number Vet CU28042021291).

\section{References}

[1] A.K.-c. Hau, T.H. Kwan, P.K.-t. Li, Melamine Toxicity and the Kidney, Journal of the American Society of Nephrology 20(2) (2009) 245.https://doi.org/10.1681/asn.2008101065.

[2] J.L. Dorne, D.R. Doerge, M. Vandenbroeck, J. Fink-Gremmels, W. Mennes, H.K. Knutsen, F. Vernazza, L. Castle, L. Edler, D. Benford, Recent advances in the risk assessment of melamine and cyanuric acid in animal feed, Toxicology and Applied Pharmacology 270(3) (2013) 218229.https://doi.org/10.1016/j.taap.2012.01.012.

[3] E.P.o.C.i.t.F. Chain, E. EFSA Panel on Food Contact Materials, Flavourings, P. Aids, Scientific Opinion on Melamine in Food and Feed, EFSA Journal 8(4) (2010)

1573.https://doi.org/10.2903/j.efsa.2010.1573.

[4] A.L. Bolden, J.R. Rochester, C.F. Kwiatkowski, Melamine, beyond the kidney: A ubiquitous endocrine disruptor and neurotoxicant?, Toxicology Letters 280 (2017) 181189.https://doi.org/10.1016/j.toxlet.2017.07.893.

[5] R.L.M. Dobson, S. Motlagh, M. Quijano, R.T. Cambron, T.R. Baker, A.M. Pullen, B.T. Regg, A.S. Bigalow-Kern, T. Vennard, A. Fix, R. Reimschuessel, G. Overmann, Y. Shan, G.P. Daston, Identification and Characterization of Toxicity of Contaminants in Pet Food Leading to an Outbreak of Renal Toxicity in Cats and Dogs, Toxicological Sciences 106(1) (2008) 251-262.https://doi.org/10.1093/toxsci/kfn160.

[6] C.-Y. Chien, C.-F. Wu, C.-C. Liu, B.-H. Chen, S.-P. Huang, Y.-H. Chou, A.-W. Chang, H.-H. Lee, C.-H. Pan, W.-J. Wu, J.-T. Shen, M.-Y. Chang, C.-H. Huang, J. Shiea, T.-J. Hsieh, M.-T. Wu, High melamine migration in daily-use melamine-made tableware, Journal of Hazardous Materials 188(1) (2011) 350-356.https://doi.org/10.1016/j.jhazmat.2011.01.128.

[7] V. Bhalla, P.C. Grimm, G.M. Chertow, A.C. Pao, Melamine nephrotoxicity: an emerging epidemic in an era of globalization, Kidney International 75(8) (2009) 774-779.https://doi.org/10.1038/ki.2009.16. 
[8] Z. Wang, H. Luo, W. Tu, H. Yang, W.H. Wong, W.T. Wong, K.F. Yung, N. Zhou, J. Zhang, X. Li, W. Guo, D. Mu, F. Li, M. Mao, Y.L. Lau, Melamine-tainted milk product-associated urinary stones in children, Pediatr Int 53(4) (2011) 489-496. https://doi.org/10.1111/j.1442-200X.2010.03284.X

[9] B. Puschner, R.H. Poppenga, L.J. Lowenstine, M.S. Filigenzi, P.A. Pesavento, Assessment of melamine and cyanuric acid toxicity in cats, J Vet Diagn Invest 19(6) (2007) 61624.https://doi.org/10.1177/104063870701900602.

[10] M.E. Thompson, M.R. Lewin-Smith, V.F. Kalasinsky, K.M. Pizzolato, M.L. Fleetwood, M.R. McElhaney, T.O. Johnson, Characterization of melamine-containing and calcium oxalate crystals in three dogs with suspected pet food-induced nephrotoxicosis, Vet Pathol 45(3) (2008) 41726.https://doi.org/10.1354/vp.45-3-417.

[11] J.Y. Yhee, C.A. Brown, C.H. Yu, J.H. Kim, R. Poppenga, J.H. Sur, Retrospective study of melamine/cyanuric acid-induced renal failure in dogs in Korea between 2003 and 2004, Vet Pathol 46(2) (2009) 348-54.https://doi.org/10.1354/vp.46-2-348.

[12] Y. Wang, F. Liu, Y. Wei, D. Liu, The effect of exogenous melamine on rat hippocampal neurons, Toxicol Ind Health 27(6) (2011) 571-6.https://doi.org/10.1177/0748233710395347.

[13] C.Y. Chu, K.O. Chu, J.Y.W. Chan, X.Z. Liu, C.S. Ho, C.K. Wong, C.M. Lau, T.L. Ting, T.F. Fok, K.P. Fung, C.C. Wang, Distribution of melamine in rat foetuses and neonates, Toxicology Letters 199(3) (2010) 398-402.https://doi.org/10.1016/j.toxlet.2010.10.004.

[14] Q.-x. Zhang, G.-y. Yang, J.-t. Li, W.-x. Li, B. Zhang, W. Zhu, Melamine induces sperm DNA damage and abnormality, but not genetic toxicity, Regulatory Toxicology and Pharmacology 60(1) (2011) 144-150.https://doi.org/10.1016/j.yrtph.2011.03.004.

[15] Y. Lv, Z. Liu, Y. Tian, H. Chen, Effect on morphology, oxidative stress and energy metabolism enzymes in the testes of mice after a 13-week oral administration of melamine and cyanuric acid combination, Regulatory Toxicology and Pharmacology 65(2) (2013) 183188.https://doi.org/10.1016/j.yrtph.2012.11.011. 
[16] S. Khan, T. Ahmad, C.V. Parekh, P.P. Trivedi, S. Kushwaha, G. Jena, Investigation on sodium valproate induced germ cell damage, oxidative stress and genotoxicity in male Swiss mice, Reproductive Toxicology 32(4) (2011) 385-394.https://doi.org/10.1016/j.reprotox.2011.09.007.

[17] F.Q. Schafer, G.R. Buettner, Redox environment of the cell as viewed through the redox state of the glutathione disulfide/glutathione couple, Free Radical Biology and Medicine 30(11) (2001) 11911212.https://doi.org/10.1016/S0891-5849(01)00480-4.

[18] M. Moshahid Khan, S.S. Raza, H. Javed, A. Ahmad, A. Khan, F. Islam, M.M. Safhi, F. Islam, Rutin Protects Dopaminergic Neurons from Oxidative Stress in an Animal Model of Parkinson's Disease, Neurotoxicity Research 22(1) (2012) 1-15.https://doi.org/10.1007/s12640-011-9295-2.

[19] M. Gałażyn-Sidorczuk, M.M. Brzóska, M. Jurczuk, J. Moniuszko-Jakoniuk, Oxidative damage to proteins and DNA in rats exposed to cadmium and/or ethanol, Chemico-Biological Interactions 180(1) (2009) 31-38.https://doi.org/10.1016/j.cbi.2009.01.014.

[20] A.F. Hamouda, A.A.E. Amin, S.S. Ibrahim, M.A. Mahmoud, Potential Ameliorative Effect of Bee Honey on Experimentally Induced Melamine Formaldehyde Toxicity in Male Rats, World 9(2) (2019) 146-157.

[21] Y.M. Abd-Elhakim, W.A.M. Mohamed, K.M. El.Bohi, H.A. Ali, F.A. Mahmoud, T.M. Saber, Prevention of melamine-induced hepatorenal impairment by an ethanolic extract of Moringa oleifera: Changes in KIM-1, TIMP-1, oxidative stress, apoptosis, and inflammation-related genes, Gene 764 (2021) 145083.https://doi.org/10.1016/j.gene.2020.145083.

[22] V. Vijayakumar, S.K. Samal, S. Mohanty, S.K. Nayak, Recent advancements in biopolymer and metal nanoparticle-based materials in diabetic wound healing management, International Journal of Biological Macromolecules 122 (2019) 137-148.https://doi.org/10.1016/j.ijbiomac.2018.10.120.

[23] K. Saravanakumar, B. Sriram, A. Sathiyaseelan, A.V.A. Mariadoss, X. Hu, K.-S. Han, V. Vishnupriya, D. MubarakAli, M.-H. Wang, Synthesis, characterization, and cytotoxicity of starchencapsulated biogenic silver nanoparticle and its improved anti-bacterial activity, International Journal of Biological Macromolecules 182 (2021) 1409-1418.https://doi.org/10.1016/j.ijbiomac.2021.05.036. 
[24] C. Jensen, J. Pallauf, Estimation of the selenium requirement of growing guinea pigs (Cavia porcellus), Journal of Animal Physiology and Animal Nutrition 92(4) (2008) 481491.https://doi.org/10.1111/j.1439-0396.2007.00738.x.

[25] W. Li, M. Guo, Y. Liu, W. Mu, G. Deng, C. Li, C. Qiu, Selenium induces an anti-tumor effect via inhibiting intratumoral angiogenesis in a mouse model of transplanted canine mammary tumor cells, Biological Trace Element Research 171(2) (2016) 371-379.https://doi.org/10.1007/s12011-015-0554-6.

[26] L. He, J. Zhao, L. Wang, Q. Liu, Y. Fan, B. Li, Y.-L. Yu, C. Chen, Y.-F. Li, Using nano-selenium to combat Coronavirus Disease 2019 (COVID-19)?, Nano Today 36 (2021) 101037.https://doi.org/10.1016/j.nantod.2020.101037.

[27] Y.-C. Chen, K.S. Prabhu, A. Das, A.M. Mastro, Dietary selenium supplementation modifies breast tumor growth and metastasis, International Journal of Cancer 133(9) (2013) 20542064.https://doi.org/10.1002/ijc.28224.

[28] D. Sun, Y. Liu, Q. Yu, X. Qin, L. Yang, Y. Zhou, L. Chen, J. Liu, Inhibition of tumor growth and vasculature and fluorescence imaging using functionalized ruthenium-thiol protected selenium nanoparticles, Biomaterials 35(5) (2014) 1572-1583.https://doi.org/10.1016/j.biomaterials.2013.11.007.

[29] N. Filipović, D. Ušjak, M.T. Milenković, K. Zheng, L. Liverani, A.R. Boccaccini, M.M. Stevanović, Comparative Study of the Antimicrobial Activity of Selenium Nanoparticles With Different Surface Chemistry and Structure, Frontiers in Bioengineering and Biotechnology 8(1591) (2021).https://doi.org/10.3389/fbioe.2020.624621.

[30] D. Peng, J. Zhang, Q. Liu, E.W. Taylor, Size effect of elemental selenium nanoparticles (Nano-Se) at supranutritional levels on selenium accumulation and glutathione S-transferase activity, Journal of Inorganic Biochemistry 101(10) (2007) 1457-1463.https://doi.org/10.1016/j.jinorgbio.2007.06.021.

[31] H. Wang, J. Zhang, H. Yu, Elemental selenium at nano size possesses lower toxicity without compromising the fundamental effect on selenoenzymes: Comparison with selenomethionine in mice, Free Radical Biology and Medicine 42(10) (2007) 15241533.https://doi.org/10.1016/j.freeradbiomed.2007.02.013.

[32] J.-S. Zhang, X.-Y. Gao, L.-D. Zhang, Y.-P. Bao, Biological effects of a nano red elemental selenium, Biofactors 15(1) (2001) 27-38. 
[33] C. Pelyhe, M. Mézes, Myths and facts about the effects of nano selenium in farm animals-minireview, Eur Chem Bull 2(12) (2013) 1049-1052.

[34] Y. Wang, X. Yan, L. Fu, Effect of selenium nanoparticles with different sizes in primary cultured intestinal epithelial cells of crucian carp, Carassius auratus gibelio, Int J Nanomedicine 8 (2013) 40074013.https://doi.org/10.2147/IJN.S43691.

[35] K.S. Abou-El-Sherbini, M.H.A. Amer, M.S. Abdel-Aziz, E.M.A. Hamzawy, W. Sharmoukh, M.M. Elnagar, Encapsulation of Biosynthesized Nanosilver in Silica Composites for Sustainable Antimicrobial Functionality, Global Challenges 2(10) (2018) 1800048.https://doi.org/10.1002/gch2.201800048.

[36] Y.M. Abd El-Hakim, A. Abdel-Rahman Mohamed, S.I. Khater, A. Hamed Arisha, M.M.M. Metwally, M.A. Nassan, M.E. Hassan, Chitosan-Stabilized Selenium Nanoparticles and Metformin Synergistically Rescue Testicular Oxidative Damage and Steroidogenesis-Related Genes Dysregulation in High-Fat Diet/Streptozotocin-Induced Diabetic Rats, Antioxidants 10(1) (2021) 17.

[37] M.M. Rashad, M.K. Galal, K.S. Abou-El-Sherbini, A.M. El-Behairy, E.M. Gouda, S.Z. Moussa, Nano-sized selenium attenuates the developmental testicular toxicity induced by di-n-butyl phthalate in pre-pubertal male rats, Biomedicine \& Pharmacotherapy 107 (2018) 1754-

1762.https://doi.org/10.1016/j.biopha.2018.09.006.

[38] D.W. Bashir, M.M. Rashad, Y.H. Ahmed, E.A. Drweesh, E.A.M. Elzahany, K.S. Abou-El-Sherbini, E.M.M. EL-Leithy, Screening the possible ameliorative impact of nanoselenium on histopathological and biochemical alterations induced by melamine toxicity on the brain of adult male albino rats, Neurotoxicology (2021 (In press)).

[39] C.K. Senthil kumaran, S. Agilan, D. Velauthapillai, N. Muthukumarasamy, M. Thambidurai, T.S. Senthil, R. Balasundaraprabhu, Synthesis and Characterization of Selenium Nanowires, ISRN Nanotechnology 2011 (2011) 589073.https://doi.org/10.5402/2011/589073.

[40] L. An, J. Fu, T. Zhang, Reversible effects of vitamins $\mathrm{C}$ and $\mathrm{E}$ combination on cognitive deficits and oxidative stress in the hippocampus of melamine-exposed rats, Pharmacology Biochemistry and Behavior 132 (2015) 152-159.https://doi.org/10.1016/j.pbb.2015.03.009.

[41] G.L. Ellman, Tissue sulfhydryl groups, Archives of biochemistry and biophysics 82(1) (1959) 7077.https://doi.org/10.1016/0003-9861(59)90090-6 
[42] H. Ohkawa, N. Ohishi, K. Yagi, Assay for lipid peroxides in animal tissues by thiobarbituric acid reaction, Analytical Biochemistry 95(2) (1979) 351-358.https://doi.org/10.1016/0003-2697(79)90738-3.

[43] M.M. Bradford, A rapid and sensitive method for the quantitation of microgram quantities of protein utilizing the principle of protein-dye binding, Analytical Biochemistry 72(1) (1976) 248-

254.https://doi.org/10.1016/0003-2697(76)90527-3.

[44] K.J. Livak, T.D. Schmittgen, Analysis of Relative Gene Expression Data Using Real-Time Quantitative PCR and the 2- $\Delta \Delta$ CT Method, Methods 25(4) (2001) 402408.https://doi.org/10.1006/meth.2001.1262.

[45] J.D. Bancroft, M. Gamble, Theory and practice of histological techniques, 6th ed. , Churchill Livingstone/Elsevier health sciences, Philadelphia, PA., 2008.

[46] S. Nath, S.K. Ghosh, S. Panigahi, T. Thundat, T. Pal, Synthesis of selenium nanoparticle and its photocatalytic application for decolorization of methylene blue under UV irradiation, Langmuir 20(18) (2004) 7880-7883.https://doi.org/10.1021/la0493181.

[47] Å. Rindlav-Westling, P. Gatenholm, Surface Composition and Morphology of Starch, Amylose, and Amylopectin Films, Biomacromolecules 4(1) (2003) 166-172.https://doi.org/10.1021/bm0256810.

[48] M. Kazemi, A. Akbari, Z. Sabouri, S. Soleimanpour, H. Zarrinfar, M. Khatami, M. Darroudi, Green synthesis of colloidal selenium nanoparticles in starch solutions and investigation of their photocatalytic, antimicrobial, and cytotoxicity effects, Bioprocess and Biosystems Engineering 44(6) (2021) 12151225.https://doi.org/10.1007/s00449-021-02515-9.

[49] J.M. Andrews, Determination of minimum inhibitory concentrations, Journal of antimicrobial chemotherapy 48(suppl_1) (2001) 5-16.

[50] S.S. Salem, M.M.G. Fouda, A. Fouda, M.A. Awad, E.M. Al-Olayan, A.A. Allam, T.I. Shaheen, Antibacterial, Cytotoxicity and Larvicidal Activity of Green Synthesized Selenium Nanoparticles Using Penicillium corylophilum, Journal of Cluster Science 32(2) (2021) 351361.https://doi.org/10.1007/s10876-020-01794-8.

[51] M. Abu-Elghait, M. Hasanin, A.H. Hashem, S.S. Salem, Ecofriendly novel synthesis of tertiary composite based on cellulose and myco-synthesized selenium nanoparticles: Characterization, antibiofilm 
and biocompatibility, International Journal of Biological Macromolecules 175 (2021) 294303.https://doi.org/10.1016/j.ijbiomac.2021.02.040.

[52] P.K. Gautam, S. Kumar, M.S. Tomar, R.K. Singh, A. Acharya, B. Ram, Selenium nanoparticles induce suppressed function of tumor associated macrophages and inhibit Dalton's lymphoma proliferation, Biochemistry and Biophysics Reports 12 (2017) 172184.https://doi.org/10.1016/j.bbrep.2017.09.005.

[53] A. Melekoğlu, H. Ekici, A. Esra, S. Karahan, Evaluation of melamine and cyanuric acid cytotoxicity: an in vitro study on L929 fibroblasts and CHO cell line, Ankara Üniversitesi Veteriner Fakültesi Dergisi 67(4) (2020) 399-406.https://doi.org/10.33988/auvfd.664059.

[54] Y.M. Abd-Elhakim, G.G. Moustafa, M.M. Hashem, H.A. Ali, K. Abo-El-Sooud, A.E. El-Metwally, Influence of the long-term exposure to tartrazine and chlorophyll on the fibrogenic signalling pathway in liver and kidney of rats: the expression patterns of collagen 1- $\alpha$, TGF $\beta-1$, fibronectin, and caspase-3 genes, Environmental Science and Pollution Research 26(12) (2019) 1236812378.https://doi.org/10.1007/s11356-019-04734-w.

[55] Q.K. Alabi, R.O. Akomolafe, O.S. Olukiran, W.J. Adeyemi, A.O. Nafiu, M.A. Adefisayo, J.G. Omole, D.I. Kajewole, O.O. Odujoko, The Garcinia kola biflavonoid kolaviron attenuates experimental hepatotoxicity induced by diclofenac, Pathophysiology 24(4) (2017) 281290.https://doi.org/10.1016/j.pathophys.2017.07.003.

[56] K. Bai, B. Hong, J. He, W. Huang, Antioxidant Capacity and Hepatoprotective Role of ChitosanStabilized Selenium Nanoparticles in Concanavalin A-Induced Liver Injury in Mice, Nutrients 12(3) (2020).https://doi.org/10.3390/nu12030857.

[57] A. Sohrabi, A.A. Tehrani, S. Asri-Rezaei, A. Zeinali, M. Norouzi, Histopathological assessment of protective effects of selenium nanoparticles on rat hepatocytes exposed to Gamma radiation, Vet Res Forum 11(4) (2020) 347-353.https://doi.org/10.30466/vrf.2018.93499.2260.

[58] K.A. Amin, K.S. Hashem, F.S. Alshehri, S.T. Awad, M.S. Hassan, Antioxidant and hepatoprotective efficiency of selenium nanoparticles against acetaminophen-induced hepatic damage, Biological Trace Element Research 175(1) (2017) 136-145.https://doi.org/10.1007/s12011-016-0748-6. 
[59] R.Z. Hamza, S.M. EL-Megharbel, T. Altalhi, A.A. Gobouri, A.A. Alrogi, Hypolipidemic and hepatoprotective synergistic effects of selenium nanoparticles and vitamin. E against acrylamide-induced hepatic alterations in male albino mice, Applied Organometallic Chemistry 34(3) (2020) e5458.https://doi.org/10.1002/aoc.5458.

[60] K. Patrick-Iwuanyanwu, M. Wegwu, E. Ayalogu, Prevention of CCI4-induced liver damage by ginger, garlic and vitamin E, Pak J Biol Sci [Internet] 10(4) (2007) 617-

21.https://doi.org/10.3923/pjbs.2007.617.621.

[61] L.P. Borges, V.C. Borges, A.V. Moro, C.W. Nogueira, J.B.T. Rocha, G. Zeni, Protective effect of diphenyl diselenide on acute liver damage induced by 2-nitropropane in rats, Toxicology 210(1) (2005) 18.https://doi.org/10.1016/j.tox.2005.01.002.

[62] M.N. Al-Seeni, H.A. El Rabey, S.M. Al-Solamy, The protective role of bee honey against the toxic effect of melamine in the male rat kidney, Toxicol Ind Health 31(6) (2015) 48593.https://doi.org/10.1177/0748233714551765.

[63] I.-C. Lee, S.-H. Kim, H.-S. Baek, S.-S. Kang, J.-C. Kim, Synergistic effect of melamine in combination with cyanuric acid on urinary tract toxicity in rats, Journal of Biomedical Research 14(3) (2013) 145-153.

[64] T. Yasui, T. Kobayashi, A. Okada, S. Hamamoto, M. Hirose, K. Mizuno, Y. Kubota, Y. Umemoto, N. Kawai, K. Tozawa, B. Gao, K. Kohri, Long-term follow-up of nephrotoxicity in rats administered both melamine and cyanuric acid, BMC Research Notes 7(1) (2014) 87.https://doi.org/10.1186/1756-0500-787.

[65] S. Peerakietkhajorn, N. Huipao, S. Hiranyachattada, Effects of Melamine and Cyanuric Acid on Renal Function and Structure in Rats, Sains Malaysiana 48(8) (2019) 17211728.http://dx.doi.org/10.17576/jsm-2019-4808-18.

[66] G. Albasher, S. Al Kahtani, M.S. Alwahibi, R. Almeer, Effect of Moringa oleifera Lam. methanolic extract on lead-induced oxidative stress-mediated hepatic damage and inflammation in rats, Environmental Science and Pollution Research 27(16) (2020) 1987719887.https://doi.org/10.1007/s11356-020-08525-6. 
[67] S.I. Khater, I. Ali, A. Ahmed, Preparation and Characterization of Chitosan-Stabilized Selenium Nanoparticles for Ameliorating Experimentally Induced Diabetic Nephropathy in Rats, Arab Journal of Nuclear Sciences and Applications 53(3) (2020) 140-

148.https://doi.org/10.21608/ajnsa.2020.19809.1300.

[68] M. Navarro-Alarcon, C. Cabrera-Vique, Selenium in food and the human body: A review, Science of The Total Environment 400(1) (2008) 115-141.https://doi.org/10.1016/j.scitotenv.2008.06.024.

[69] A. Khurana, S. Tekula, M.A. Saifi, P. Venkatesh, C. Godugu, Therapeutic applications of selenium nanoparticles, Biomedicine \& Pharmacotherapy 111 (2019) 802-

812.https://doi.org/10.1016/j.biopha.2018.12.146.

[70] L.-J. Su, J.-H. Zhang, H. Gomez, R. Murugan, X. Hong, D. Xu, F. Jiang, Z.-Y. Peng, Reactive Oxygen Species-Induced Lipid Peroxidation in Apoptosis, Autophagy, and Ferroptosis, Oxidative Medicine and Cellular Longevity 2019 (2019) 5080843.https://doi.org/10.1155/2019/5080843.

[71] N.K. Mondal, H. Saha, B. Mukherjee, N. Tyagi, M.R. Ray, Inflammation, oxidative stress, and higher expression levels of Nrf2 and NQO1 proteins in the airways of women chronically exposed to biomass fuel smoke, Molecular and Cellular Biochemistry 447(1) (2018) 63-

76.https://doi.org/10.1007/s11010-018-3293-0.

[72] A.M. Sheiha, S.A. Abdelnour, M.E. Abd El-Hack, A.F. Khafaga, K.A. Metwally, J.S. Ajarem, S.N. Maodaa, A.A. Allam, M.T. El-Saadony, Effects of Dietary Biological or Chemical-Synthesized NanoSelenium Supplementation on Growing Rabbits Exposed to Thermal Stress, Animals 10(3) (2020) 430.

[73] Z. Xu, Z. Wang, J.-j. Li, C. Chen, P.-c. Zhang, L. Dong, J.-h. Chen, Q. Chen, X.-t. Zhang, Z.-1. Wang, Protective effects of selenium on oxidative damage and oxidative stress related gene expression in rat liver under chronic poisoning of arsenic, Food and Chemical Toxicology 58 (2013) 17.https://doi.org/10.1016/j.fct.2013.03.048.

[74] A.A. Khalaf, W. Ahmed, W.A. Moselhy, B.R. Abdel-Halim, M.A. Ibrahim, Protective effects of selenium and nano-selenium on bisphenol-induced reproductive toxicity in male rats, Hum Exp Toxicol 38(4) (2019) 398-408.https://doi.org/10.1177/0960327118816134. 
[75] N.M. Shafik, M.M. El Batsh, Protective effects of combined selenium and Punica granatum treatment on some inflammatory and oxidative stress markers in arsenic-induced hepatotoxicity in rats, Biological Trace Element Research 169(1) (2016) 121-128.https://doi.org/10.1007/s12011-015-0397-1.

[76] A.L. Stefanson, M. Bakovic, Dietary Regulation of Keap1/Nrf2/ARE Pathway: Focus on PlantDerived Compounds and Trace Minerals, Nutrients 6(9) (2014).https://doi.org/10.3390/nu6093777.

[77] C. Zhang, J. Lin, J. Ge, L.-L. Wang, N. Li, X.-T. Sun, H.-B. Cao, J.-L. Li, Selenium triggers Nrf2mediated protection against cadmium-induced chicken hepatocyte autophagy and apoptosis, Toxicology in Vitro 44 (2017) 349-356.https://doi.org/10.1016/j.tiv.2017.07.027.

[78] T.-J. Hsieh, P.-C. Hsieh, Y.-H. Tsai, C.-F. Wu, C.-C. Liu, M.-Y. Lin, M.-T. Wu, Melamine Induces Human Renal Proximal Tubular Cell Injury via Transforming Growth Factor- $\beta$ and Oxidative Stress, Toxicological Sciences 130(1) (2012) 17-32.https://doi.org/10.1093/toxsci/kfs231.

[79] G. Salvesen, Program in apoptosis and cell death research, The Burnham Institute, Chem. Rev 102 (2002) 4489-4500.

[80] A.R. Hashim, D.W. Bashir, N.A.E. Yasin, M.K. Galal, E.-G.S. M, Ameliorative effect of Nacetylcysteine against glyphosate-induced hepatotoxicity in adult male albino rats: histopathological, biochemical, and molecular studies, Environmental Science and Pollution Research (2021).https://doi.org/10.1007/s11356-021-13659-2.

[81] A. Albihn, J. Lovén, J. Ohlsson, L.M. Osorio, M. Henriksson, c-Myc-dependent etoposide-induced apoptosis involves activation of Bax and caspases, and PKCdelta signaling, Journal of Cellular Biochemistry 98(6) (2006) 1597-1614.https://doi.org/10.1002/jcb.20816.

[82] A.J. Yiu, C.-L. Ibeh, S.K. Roy, B.C. Bandyopadhyay, Melamine induces Ca2+-sensing receptor activation and elicits apoptosis in proximal tubular cells, American Journal of Physiology-Cell Physiology 313(1) (2017) C27-C41.https://doi.org/10.1152/ajpcell.00225.2016.

[83] X. Yuan, Z. Fu, P. Ji, L. Guo, A.O. Al-Ghamdy, A. Alkandiri, O.A. Habotta, A.E. Abdel Moneim, R.B. Kassab, Selenium Nanoparticles Pre-Treatment Reverse Behavioral, Oxidative Damage, Neuronal Loss and Neurochemical Alterations in Pentylenetetrazole-Induced Epileptic Seizures in Mice, International Journal of Nanomedicine 15 (2020) 6339-6353.https://doi.org/10.2147/ijn.s259134. 
[84] H.A. Fahmy, A.S. Abd El Azim, O.A. Gharib, Protective Effects of omega-3 fatty acids and/or Nano-selenium on Cisplatin and Ionizing radiation induced liver toxicity in rats, Indian Journal of Pharmaceutical Education and Research 50(4) (2016) 649-655.https://doi.org/10.5530/ijper.50.4.17. 


\section{List of Figures}
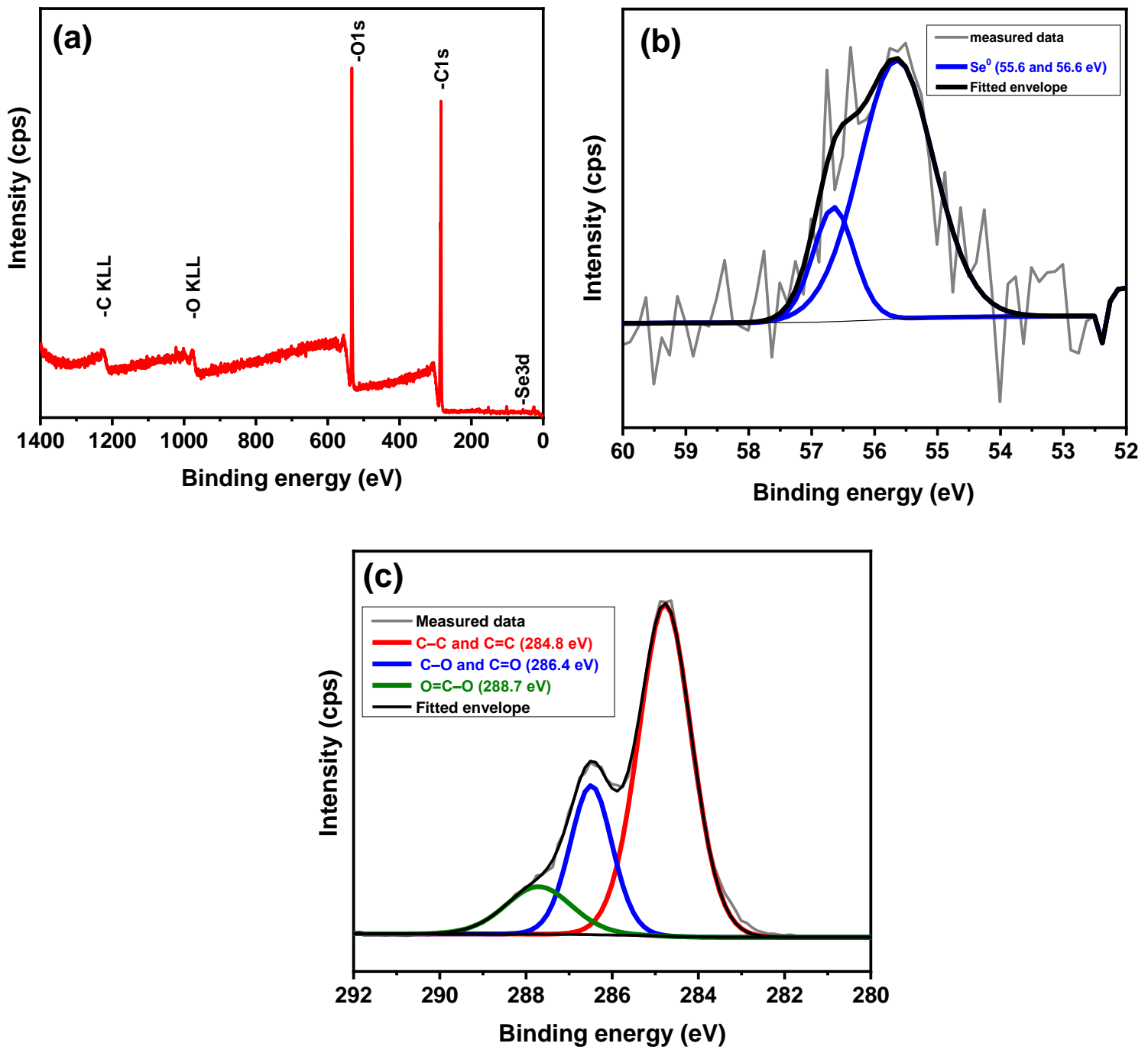

Fig. 1. (a-c) XPS analysis of Se-NPs@starch. The spectra are fitted with a linear combination of the corresponding reference spectra. 


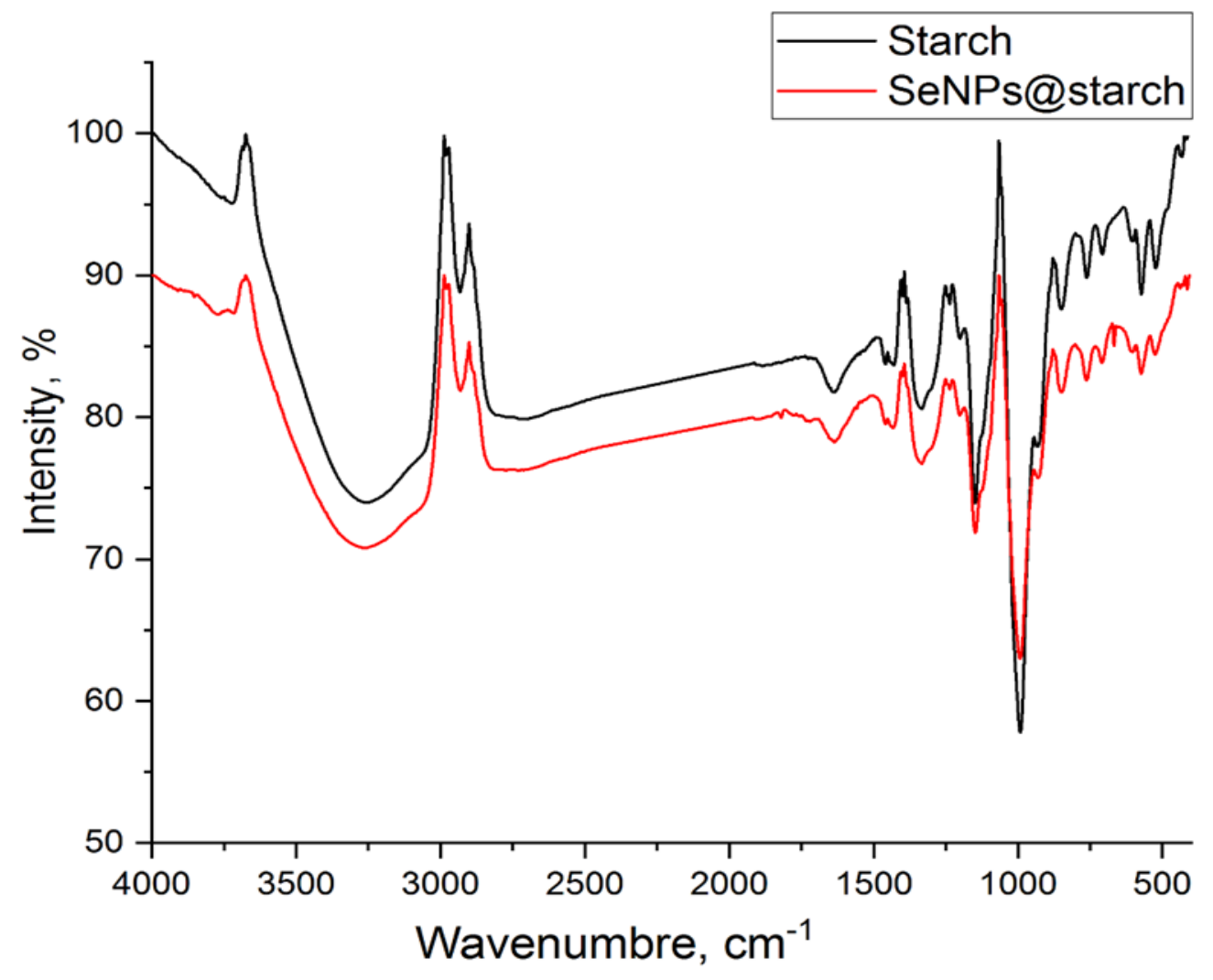

Fig. 2. FTIR spectrum of the Se-NPs@ starch compared with the free starch. 

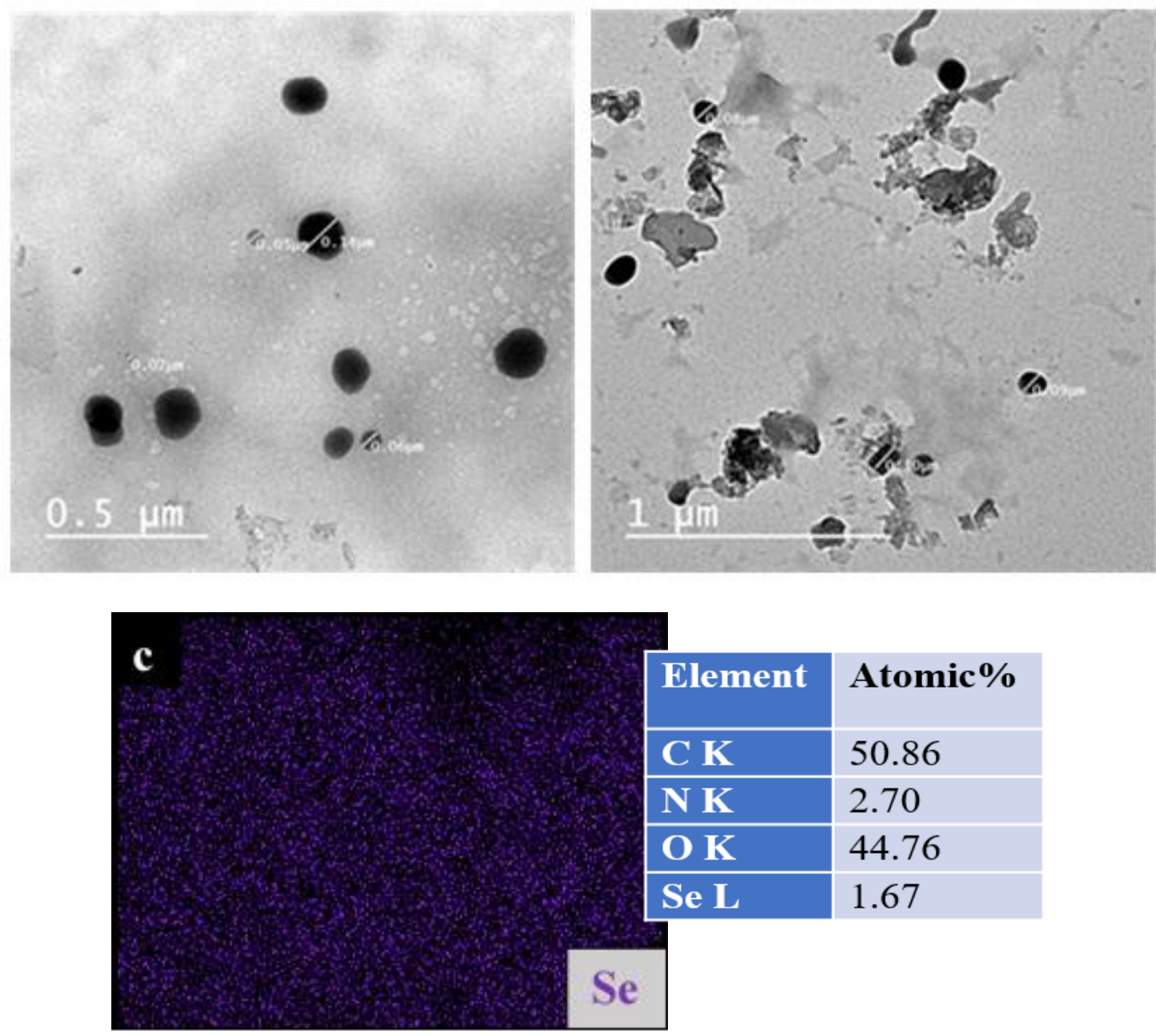

Fig. 3. (a and b) TEM images and (c) EDS elemental mapping of Se-NPs@ starch. 
A

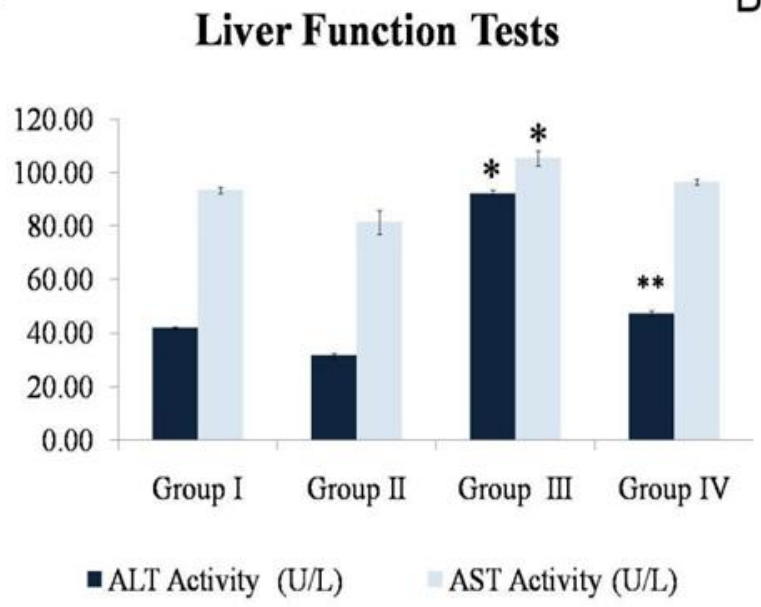

B
Kidney Function Tests

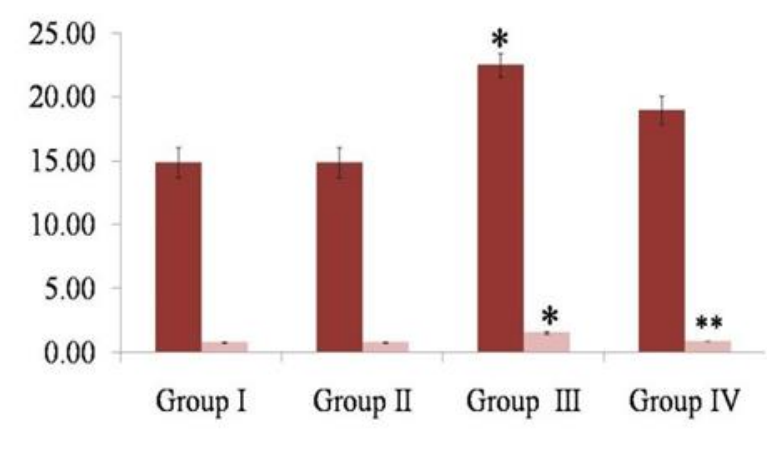

- Serum Urea $(\mathrm{mg} / \mathrm{dl}) \quad$ = Serum creatinine $(\mathrm{mg} / \mathrm{dl})$

Fig. 4. Protective effects of Se-NPs against the melamine-induced hepatic (A) and renal (B) damage in male rats. Data are presented as mean \pm SEM. *indicates statistically different from the control negative group ( $p<$ $0.05)$.** indicates statistically different from the melamine-treated group $(p<0.05)$

A

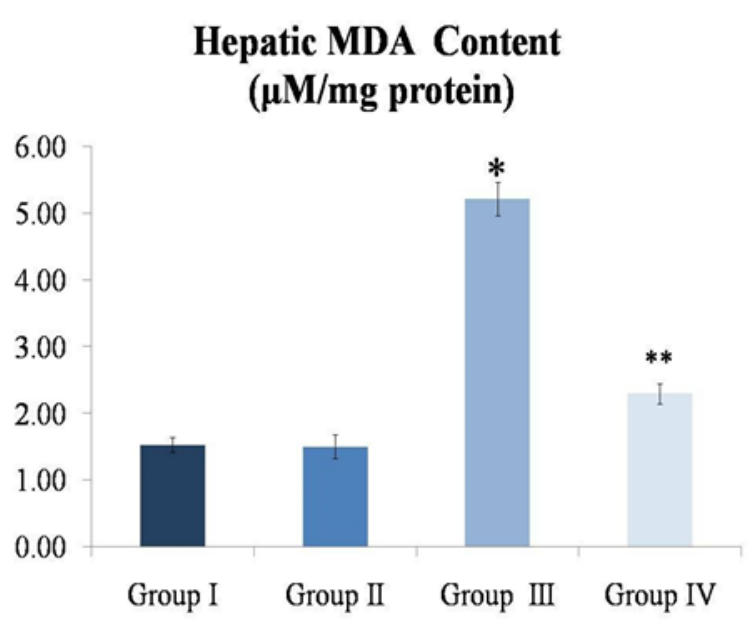

B

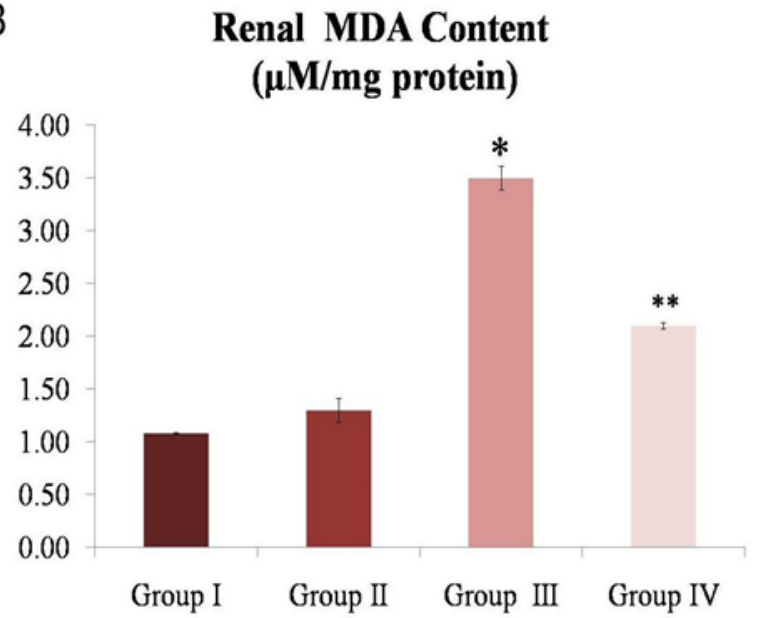

Fig. 5. Protective effects of Se-NPs against the melamine-induced high level of MDA $(\mu \mathrm{M} / \mathrm{mg}$ protein) in albino rats. Data are presented as mean \pm SEM. *indicates statistically different from the control negative group $(p<0.05)$.** indicates statistically different from the melamine-treated group $(p<0.05)$ 
A

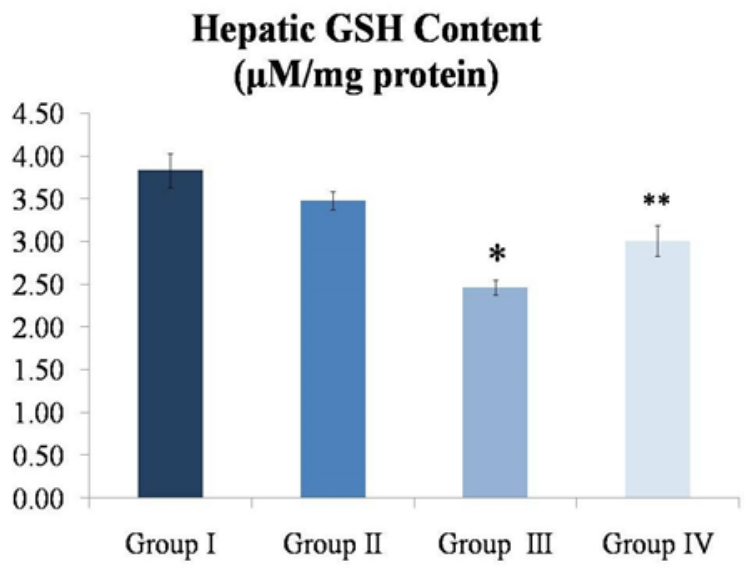

B

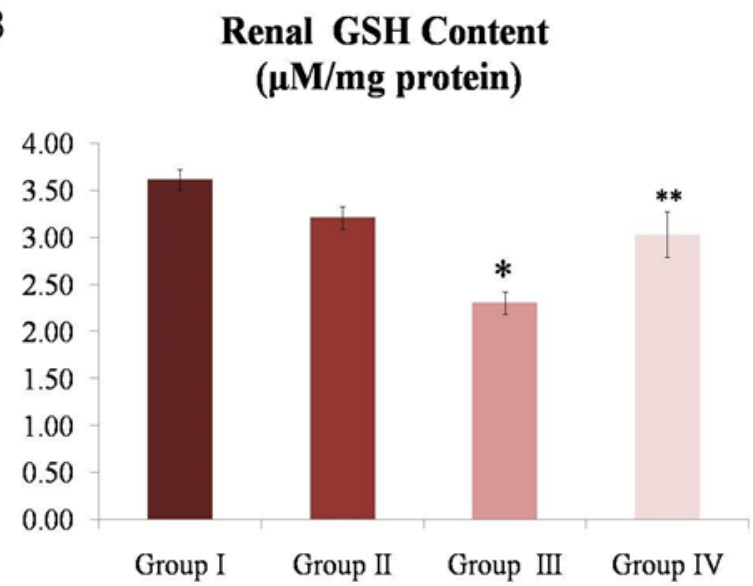

Fig. 6. Protective effects of Se-NPs against the melamine induced reduction level of GSH ( $\mu \mathrm{M} / \mathrm{mg}$ protein) in albino rats. Data are presented as mean \pm SEM. *indicates statistically different from the control negative group $(p<0.05)$.** indicates statistically different from the melamine-treated group $(p<0.05)$

A

\section{Antioxidant Related Genes}

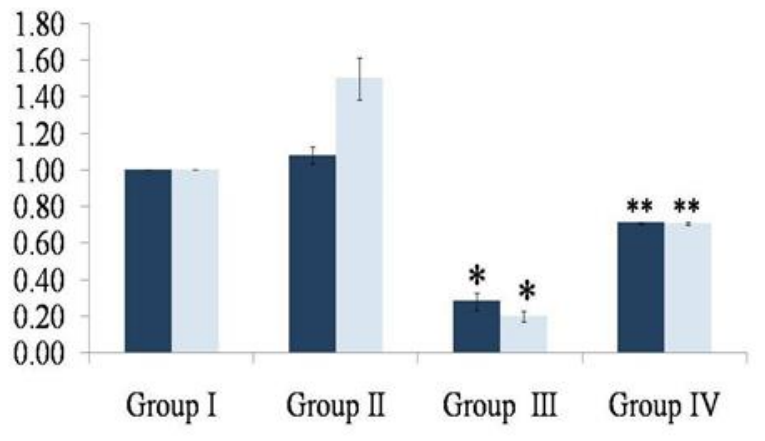

- Hepatic mRNA Relative Expression for Nrf 2 gene Hepatic mRNA Relative Expression for GPx gene
B

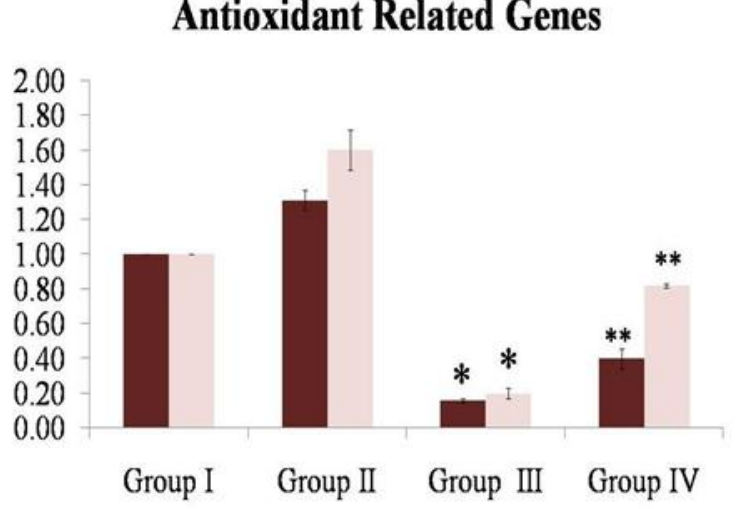

- Renal mRNA Relative Expression for Nrf 2 gene Renal mRNA Relative Expression for GPx gene

Fig. 7. Protective effects of Se-NPs against the melamine-induced downregulation of some antioxidant related genes in male albino rats. (A) Hepatic $N r f 2$ and $G P x$ genes, (B) Renal $N r f 2$ and GPX genes. Data are presented as mean \pm SEM. *indicates statistically different from the control negative group $(p<0.05)$. ** indicates statistically different from the melamine-intoxicated group $(p<0.05)$ 
A

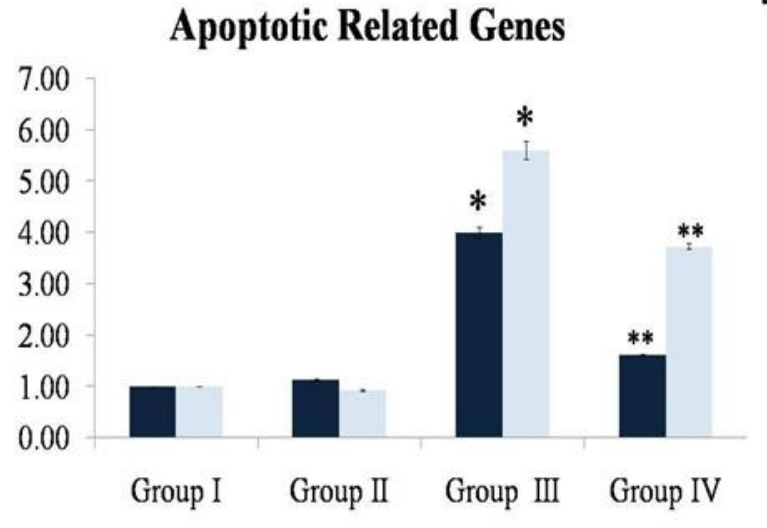

- Hepatic mRNA Relative Expression for c-Myc gene Hepatic mRNA Relative Expression for CASP 3 gene
B

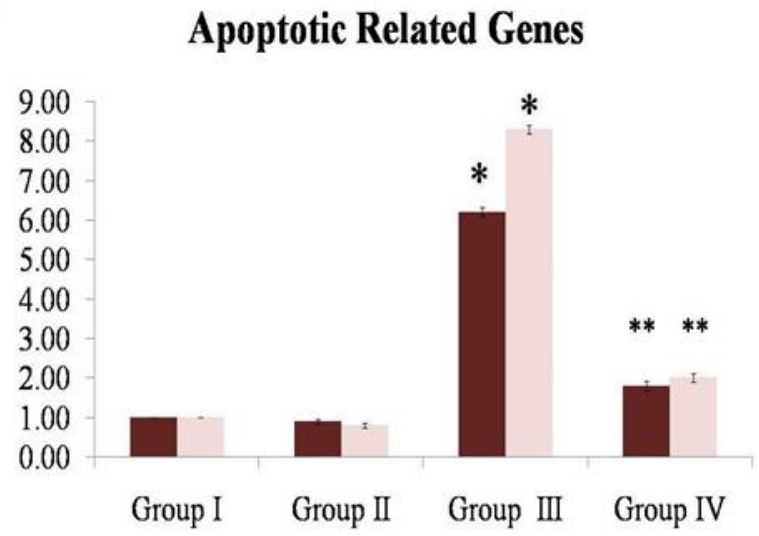

- Renal mRNA Relative Expression for c-Myc gene Renal mRNA Relative Expression for CASP 3 gene

Fig. 8. Ameliorative effects of Se-NPs against the melamine-induced upregulation of some apoptotic related genes in male albino rats. (A) Hepatic $c-M y c$ and CASP3 genes, (B) Renal $c-M y c$ and CASP3 genes. Data are presented as mean \pm SEM *indicates statistically different from the control negative group $(p<0.05)$. ** indicates statistically different from the melamine-intoxicated group $(p<0.05)$ 

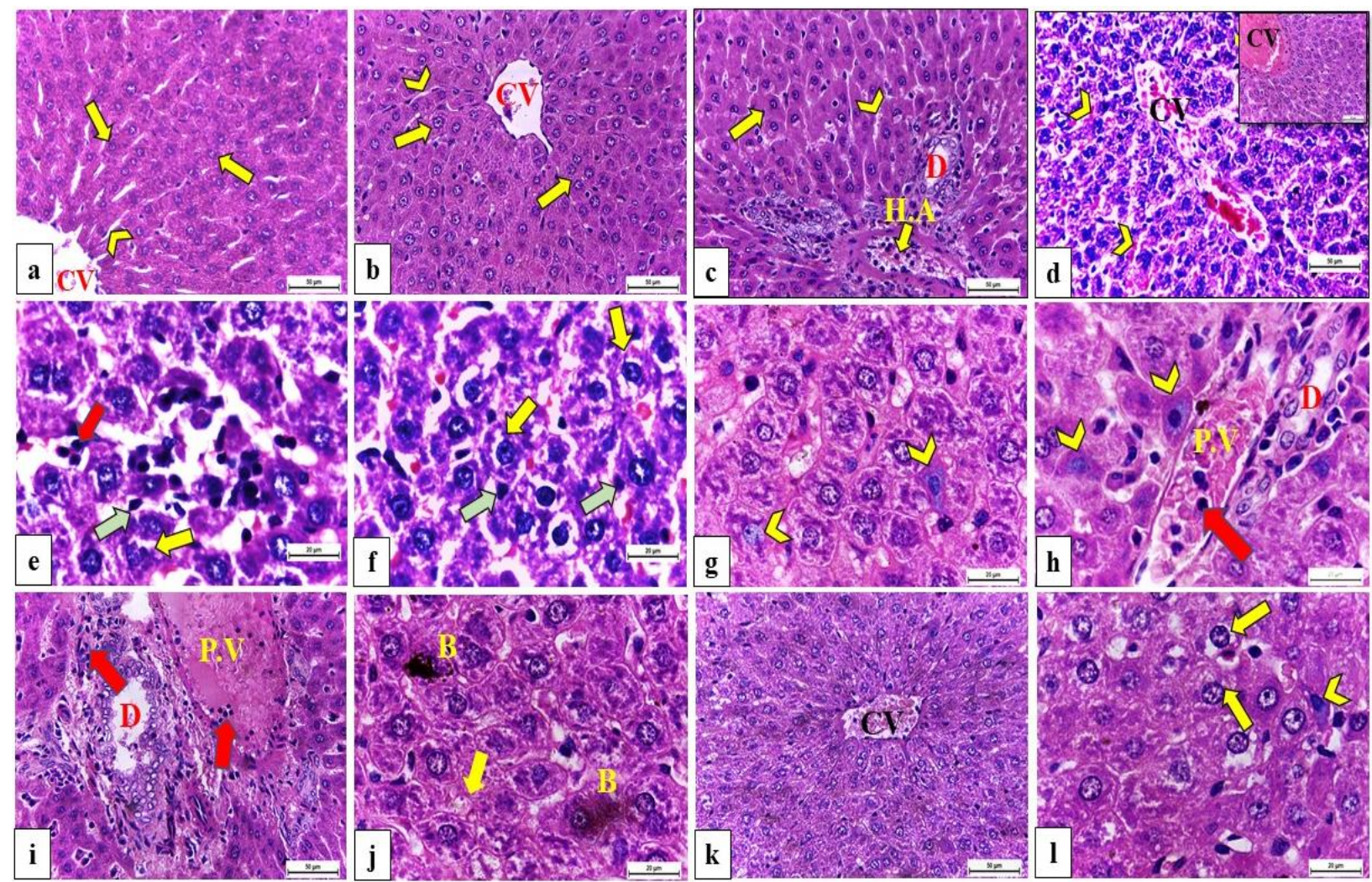

a: Control group; b, c: Nano-selenium group; $d$-j: Melamine group; $\mathrm{k}$, l: Melamine and nano-selenium group.

Fig. 9. A photomicrograph of $H \& E$-stained sections of rats' hepatic tissues showing:

a (X400): The control group revealing normal cords of hepatocytes (arrow) that appeared radiating from normal central vein (CV) and separated by normal hepatic sinusoids (chevron). The hepatocytes of the control group appeared polyhedral with central, vesicular, and spherical nuclei. b, c (X400): The nano-selenium exposed group exhibiting nearly normal architecture of the central vein (CV) and hepatocytes (arrow) separated by normal hepatic sinusoids (chevron). The portal area (c) showing intact architecture of the bile duct (D) and branches of the portal vein and hepatic artery (H.A) d-j: The melamine-exposed group. d (400X): Hepatic tissue showing distortion of hepatic cords arrangement, edema, sever congestion and dilatation of the central vein (CV) and hepatic sinusoids (chevron). e, f (X1000): Blood sinusoids appear dilated with bulged activated Von Kupffer cells (green arrow), in addition to inflammatory cells infiltration (e: red arrow). Also, hepatocytes displaying ballooning and cytoplasmic vacuolization (yellow arrow). $\mathbf{g}$, h (X1000): Different stages of hepatocyte degeneration and necrosis are clearly seen (chevron). h, i (X1000): Portal area exhibiting congestion of the portal vein (P.V), distortion of the epithelial lining of the bile duct branches (D) and inflammatory cells infiltration (red arrow). $\mathbf{j}$ (X1000): Dark brown deposition inside the hepatocytes (B) is clearly noticed. K (X400), I (X1000): Melamine-exposed rats co-treated with Se-NPs@starch showed partial recovery that is observed in the form of moderate congestion of the central vein $(\mathrm{CV})$ and less degenerative changes (chevron) of the hepatic parenchyma, particularly hepatocytes that show less ballooning and cytoplasmic vacuolization (arrow) 

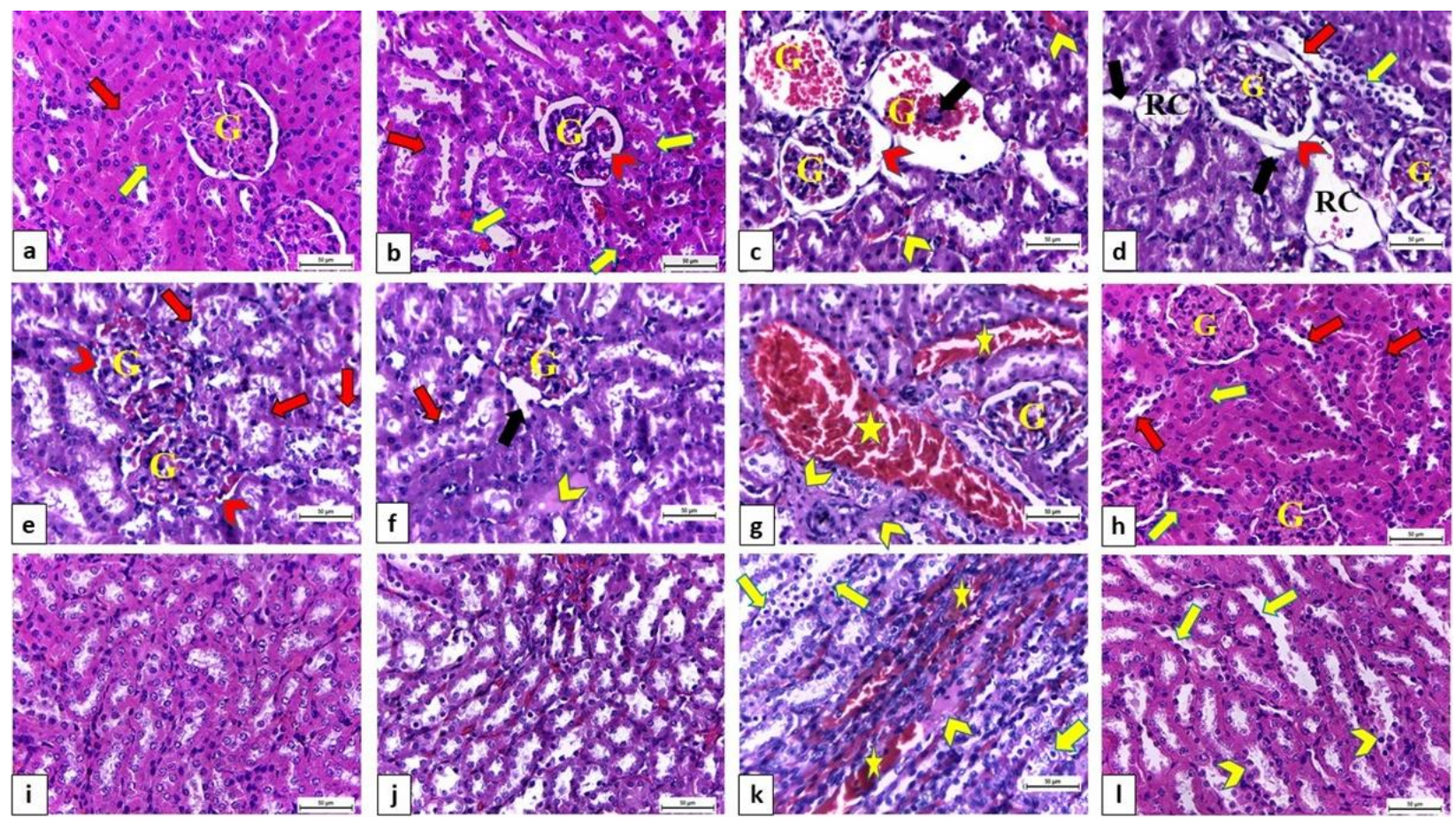

a, i: Control group; $b$, j: Nano-selenium group; $c-g$ and $k$ : Melamine group; $h$, l: Melamine and nano-selenium group

\section{Fig. 10. A photomicrograph of H\&E-stained sections of rats' renal tissues at X400 showing:}

a: The control group revealing normal structure of the renal corpuscle containing glomerulus (G), PCT (yellow arrow) and DCT (red arrow). b: The Se-NPs@ @ starch exposed group revealed nearly normal glomerular tuft (G) with plentiful capsular space enveloped by intact Bowman's capsule (chevron), intact tubular epithelial cells of PCT (yellow arrow) and DCT (red arrow). c-g: The melamine-exposed group with various histopathological alterations. c: Some renal corpuscles exhibiting widening of capsular space (red chevron) and congestion of glomerular tuft (G) with hypocellularity of mesangial cells (black arrow). Furthermore, interstitial congestion (yellow chevron) is observed. d: Some renal corpuscles (RC) demonstrating loss of glomeruli with peri-glomerular edema (black arrow), while others showing congestion of glomerulus $(\mathrm{G})$ with widened capsular spaces (red chevron). Also, some degenerated DCT were lined by squamous cells (red arrow) and possess vacuolization and desquamation of other lining cells with pyknosis (yellow arrow). e: Some renal corpuscles show congested glomeruli (G) with narrowed capsular spaces (red chevron). Moreover, degenerated renal tubules (red arrow) were plentiful. f: Distorted renal corpuscle with diminished glomerular tuft $(\mathrm{G})$ and discontinuous Bowman's capsule (black arrow) are clearly observed. Degenerated renal tubules with desquamated epithelial cells (red arrow) are also noticed in addition to hyalinization (yellow chevron). g: Severe vascular congestion (yellow star) and hyalinization (yellow chevron) are observed. h: The melamine-exposed rats co-treated with Se-NPs@starch show restoration of most renal corpuscles, glomeruli (G) and renal tubules (yellow arrow), while some renal tubules still show degeneration (red arrow). i: Renal medulla of the control group revealing normal structure of collecting tubules. j: The Se-NPs@ starch exposed group exhibiting nearly normal collecting tubules of medulla. k: The melamine-exposed group show prominent vacuolar degeneration of collecting tubules (yellow arrow), hyalinization (yellow chevron), and congestion of interstitial blood capillaries (yellow star). I: The melamine-exposed group co-treated with Se-NPs@starch demonstrating partial recovery of renal medulla with less degenerated collecting tubules (yellow chevron). Also, some collecting tubules appear with squamous lining cells (yellow arrow) 

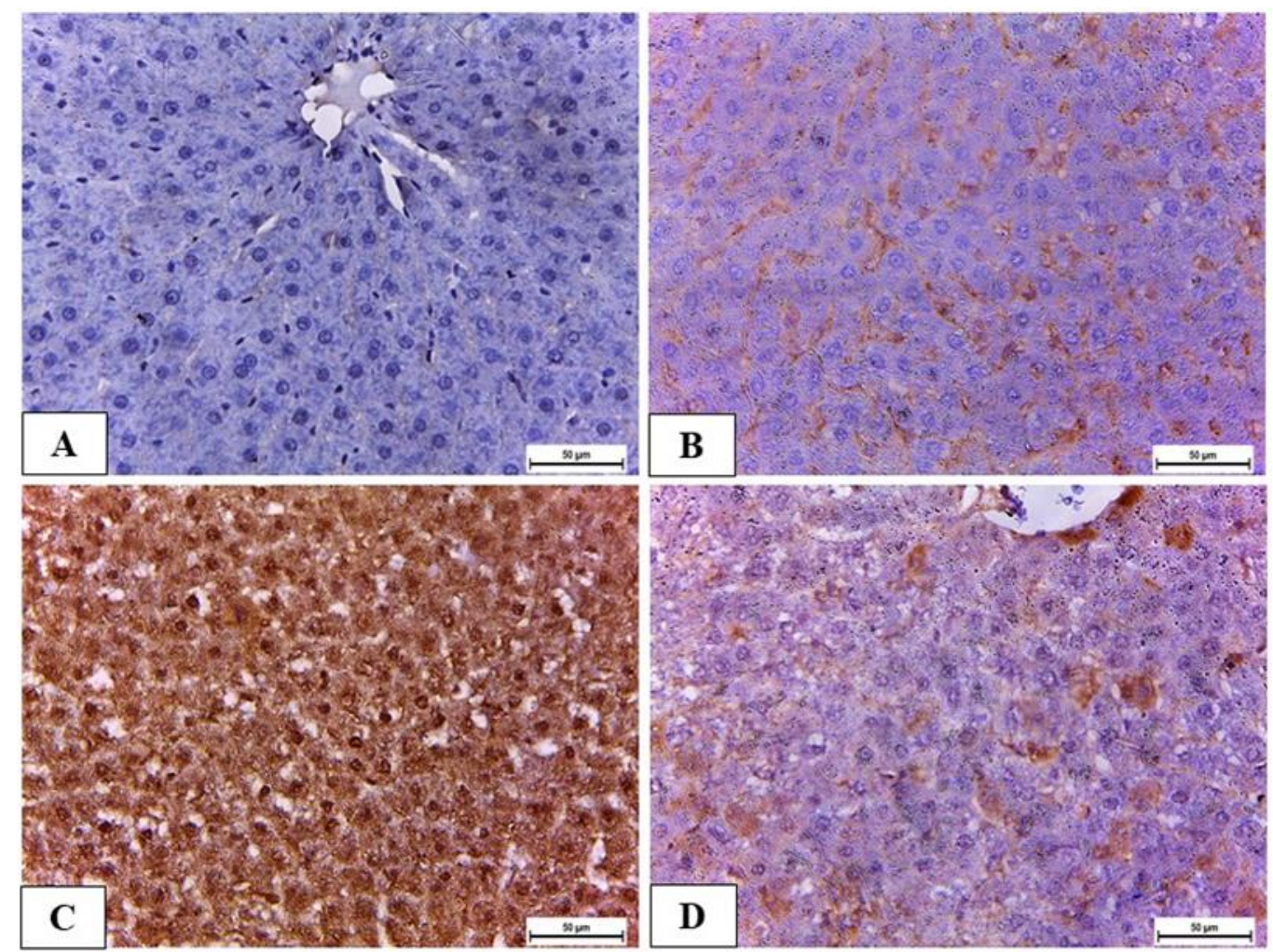

Fig. 11. A photomicrograph demonstrating immune expression in the caspase 3 stained liver sections (x400).

A \& B. Negative caspase expression in the hepatic tissue obtained from the control (A) and Se-NPs@ starch treated group (B). C. Intense expression in the melamine-exposed group. D. Mild expression in the melamine-exposed group co-treated with nano-selenium 

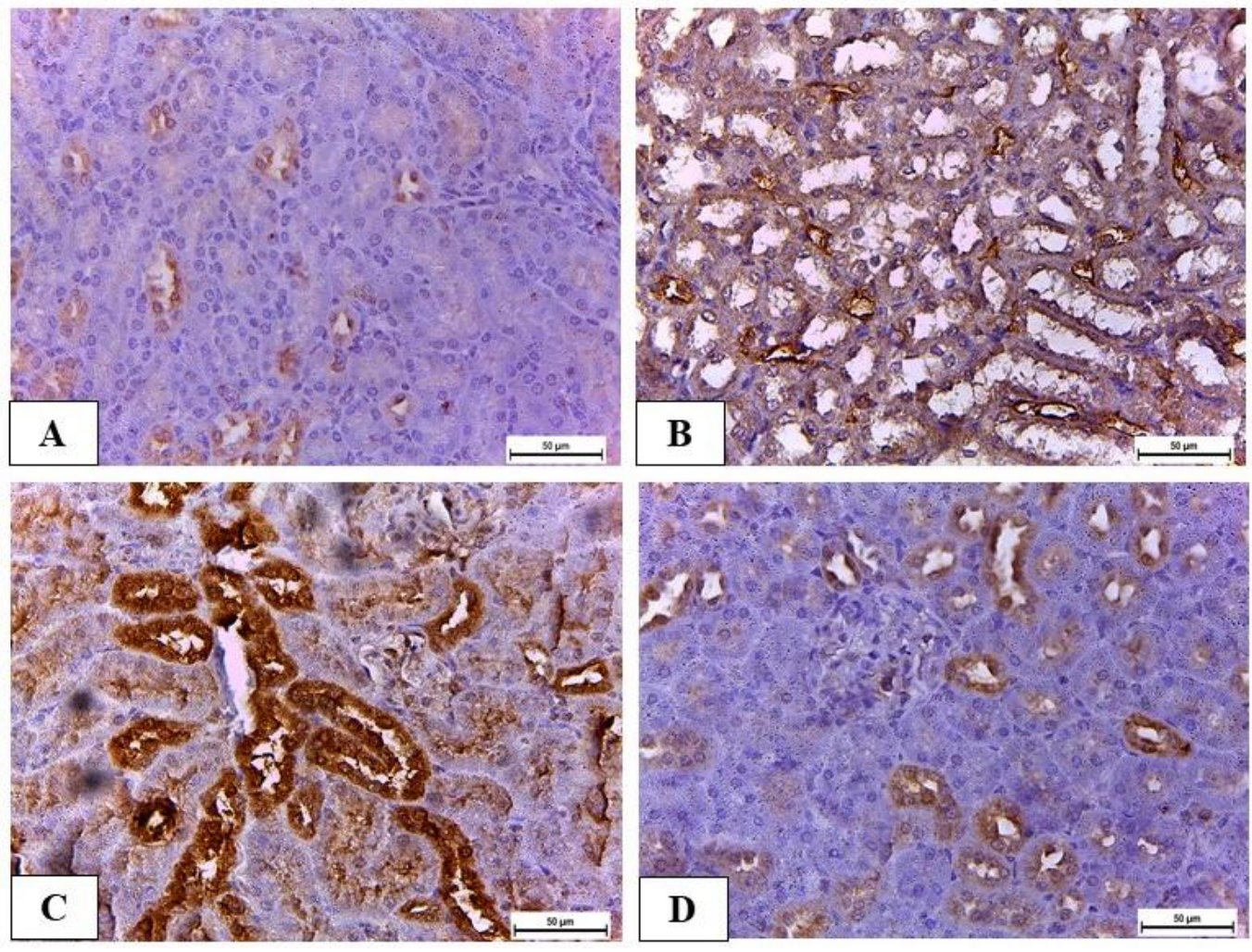

Fig. 12. A photomicrograph demonstrating caspase 3 expression in the renal tissue sections $(x 400)$.

A \& B. Mild positive expression in the renal tissue obtained from the control (A) and Se-NPs@starch exposed group (B). C. Intense expression in the melamine-exposed group. D. Moderate expression in the melamineexposed group co-treated with Se-NPs@starch. 

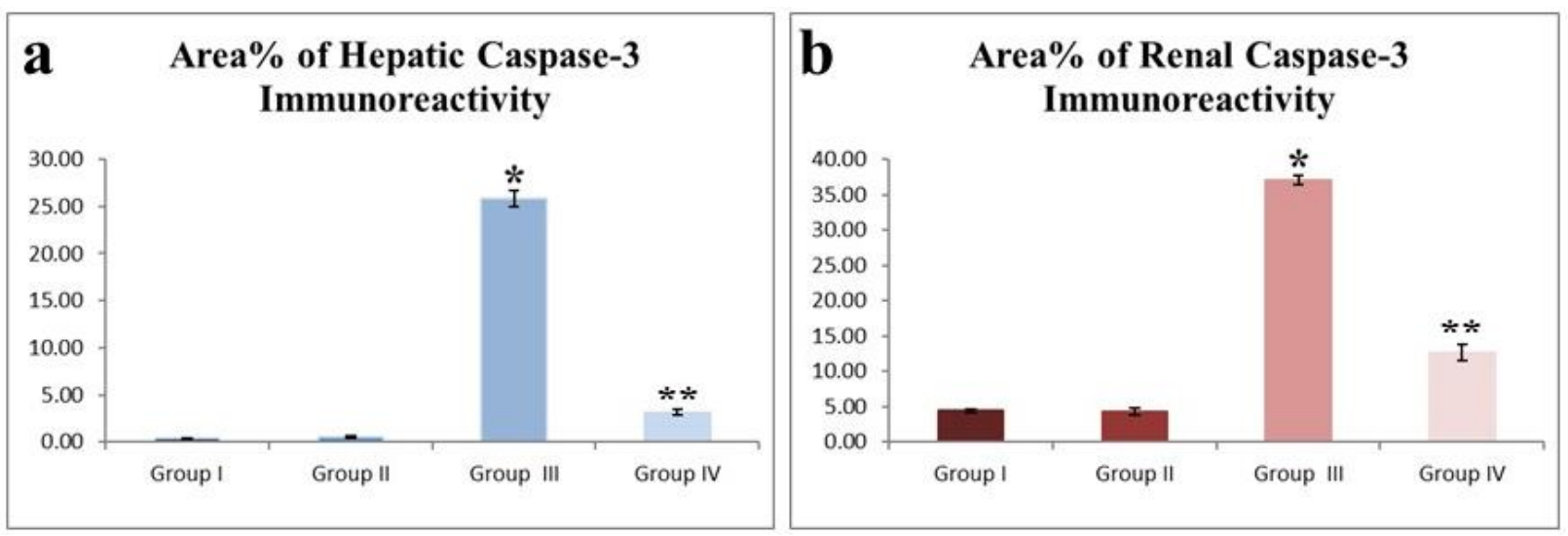

Fig. 13. Morphometrical analysis representing the protective effect of Se-NPs against the melamine-induced high area \% of the hepatic (A) and renal (B) caspase 3-stained sections in rats. Data are presented as mean \pm SEM ( $\mathrm{n}=5$ fields / group). * indicates statistically different from the control negative group $(p<0.05)$. ** indicates statistically different from the melamine-intoxicated group $(p<0.05)$ 


\section{List of Tables}

Table 1. Primer sequence used for $q R T-P C R$.

\begin{tabular}{|l|l|l|l|}
\hline $\begin{array}{l}\text { Gene } \\
\text { symbol }\end{array}$ & Gene description & $\begin{array}{l}\text { Accession } \\
\text { number }\end{array}$ & Primer Sequence \\
\hline GAPDH & $\begin{array}{l}\text { Glyceraldehyde3-phosphate } \\
\text { dehydrogenase }\end{array}$ & NC_005103.4 & $\begin{array}{l}\text { F:- 5'-ACCACAGTCCATGCCATCAC-3' } \\
\text { R:- 5'-TCCACCACCCTGTTGCTGTA-3' }\end{array}$ \\
\hline Nrf 2 & Nuclear factor, erythroid 2-like 2 & NC_005102.4 & $\begin{array}{l}\text { F: -5'-GGCCCTCAATAGTGCTCAG-3' } \\
\text { R:-5'-TAGGCACCTGTGGCAGATTC-3' }\end{array}$ \\
\hline$G P_{X}$ & Glutathione peroxidase & M21210.1 & $\begin{array}{l}\text { F:- 5'-CTCTCCGCGGTGGCACAGT-3' } \\
\text { R:- 5-CCACCACCGGGTCGGACATAC-3 }\end{array}$ \\
\hline$c-M y c$ & Cytochrome c & K00750.1 & $\begin{array}{l}\text { F :- 5'-TAC CC T CTC AAC GAC AGC AG-3' } \\
\text { R:- 5'-TCT TGA CAT TCT CCT CGG TG-3' }\end{array}$ \\
\hline CASP 3 & Caspase 3 & NM_012922.2 & $\begin{array}{l}\text { F: -5'-GGAGCTTGGAACGCGAAGAA-3' } \\
\text { R:-5'-ACACAAGCCCATTTCAGGGT-3' }\end{array}$ \\
\hline
\end{tabular}

